\title{
El pueblo gunadule a través de la mirada fotográfica de los misioneros carmelitas descalzos en la prefectura apostólica de Urabá, Colombia (1918-1941)
}

\section{The Gunadule People Through the Photographic Gaze of the Barefoot Carmelite Missionaries in the Apostolic Prefecture of Urabá, Colombia (1918-1941) \\ O povo Gunadule através do olhar fotográfico dos missionários Carmelitas Descalços da Prefeitura Apostólica de Urabá, Colômbia (1918-1941)}

\begin{abstract}
Resumen: Desde finales del siglo XIX y durante el XX se produjo una reactivación de la actividad misional a nivel global. En Colombia, este renacer otorgó un papel protagónico a la Iglesia Católica en las tareas de incorporar a la nación a las poblaciones indígenas que vivían al margen del Estado. Los estudios que analizan el papel de las misiones en el avance estatal hacia territorios «baldíos» en Colombia no han tenido en cuenta las representaciones que los religiosos construyeron sobre los pueblos originarios que debían «civilizar». En estas representaciones se clasificó a dichas poblaciones a partir de criterios raciales y culturales que dotaban de sentido a la actuación misional y, a su vez, legitimaban el nuevo orden republicano. Por ello, en este artículo se analizan las representaciones que los misioneros carmelitas descalzos construyeron sobre el pueblo gunadule de la región del golfo de Urabá. Para emprender esta tarea utilizaremos unas fuentes poco trabajadas, las fotografías.
\end{abstract}

Palabras claves: historia; historia cultural; fotografías; Colombia; obra misionera; población indígena. 


\begin{abstract}
From the end of the XIX century and during the XX there was a reactivation of missionary activity at a global level. In Colombia, this rebirth gave a leading role to the Catholic Church in the tasks of incorporating into the nation the indigenous populations that lived outside the State. The studies that analyze the role of the missions in the state advance towards «wasteland» territories in Colombia, have not considered the representations that the religious built on the native peoples that they had to «civilize». Through these, they classified these populations based on racial and cultural criteria that gave meaning to missionary action and, in turn, legitimized the new republican order. For this reason, in this article we want to analyze the representations that the barefoot Carmelite missionaries built on the gandule people of the gulf of Urabá region. To undertake this task, we will use some little worked sources, the photographs.
\end{abstract}

Keywords: history; cultural history; photographs; Colombia; missionary work; indigenous peoples.

Resumo: A partir do final do século XIX e durante o século XX, houve uma reativação da atividade missionária em nível global. Na Colômbia, esse renascimento deu um papel de liderança à Igreja Católica na tarefa de incorporar à nação as populações indígenas que viviam fora do Estado. Os estudos que analisam o papel das missões no avanço do Estado rumo aos territórios «vagos» na Colômbia não levam em consideração as representações que os religiosos construíram sobre os povos originários que deveriam «civilizar». Nessas representações, essas populações foram classificadas a partir de critérios raciais e culturais que deram sentido à ação missionária e, por sua vez, legitimaram a nova ordem republicana. Por isso, este artigo pretende analisar as representações que os missionários carmelitas descalços construíram sobre o povo Gunadule da região do Golfo do Urabá. Para realizar esta tarefa utilizaremos algumas fontes pouco trabalhadas, as fotografias.

Palavras chaves: história; história cultural; fotografias; Colômbia; trabalho missionário; população indigena.

\title{
Introducción ${ }^{1}$
}

$\mathrm{E}$ n los trescientos años de dominio castellano del territorio americano, muchos de los espacios que integraban el imperio hispano no fueron controlados ni incorporados de forma efectiva a este. Ya fuese por la falta de interés económico -poca concentración de población indígena, recursos naturales escasos, o de difícil acceso-, por la resistencia persistente y efectiva de los indígenas de la región o por la imposibilidad material de realizar una ocupación efectiva, se fueron conformando como territorios fronterizos. Tras los procesos emancipatorios, los

1 Este trabajo forma parte de mi tesis doctoral «"Convertir para Dios y transformar para la patria”. Misioneros claretianos y carmelitas descalzos entre los "indios errantes” del Chocó y Urabá, Colombia (19081952)», defendida en Barcelona en noviembre del 2018. 
grupos dirigentes de las nuevas Repúblicas, ante la necesidad de conformar un Estado nación, tuvieron que prestar atención a esos espacios fronterizos y hacer un esfuerzo por controlarlos e incorporar a las poblaciones indígenas que estaban en los márgenes. Para llevarlo a cabo, según apuntan distintos investigadores e investigadoras que han abordado las problemáticas referidas a los proyectos diseñados e implementados por los grupos dirigentes republicanos para ocupar y controlar los territorios fronterizos, con vistas a la salvaguarda de sus fronteras internacionales y a la eliminación de sus fronteras internas, se le otorgó un papel protagónico a la Iglesia Católica a la cual, a través de las misiones, se le confiaron las tareas de explorar, establecer presencia efectiva del Estado, propiciar la explotación económica de los recursos naturales existentes en esos territorios e incorporar a los pueblos «bárbaros» $\mathrm{y}$ «salvajes» al cuerpo de la nación mediante la evangelización de estos, pues se consideraba que esta era una premisa básica para poder alcanzar la «civilización». Así, los misioneros implementaron un conjunto de prácticas que tenían la finalidad de convertir a los paganos indígenas al catolicismo, y transformarlos en ciudadanos de la nación; lo que implicaba implantarles no solo una nueva cosmovisión, sino también una praxis social «civilizada». ${ }^{2}$

En las últimas décadas han proliferado los trabajos que se centran en analizar el papel de las misiones en las tareas de colonización de esos territorios fronterizos en distintos países latinoamericanos. El proyecto colonizador, evangelizador y «civilizador» de los salesianos en la Patagonia argentina fue trabajado por María Andrea Nicoletti. ${ }^{3}$ Pilar García Jordán estudió el proyecto teórico franciscano y las praxis implementadas por ellos en la conquista y reducción de los guarayos en Bolivia. ${ }^{4}$ Para el caso colombiano se han elaborado diversos estudios que abordan el papel de las misiones en el avance territorial hacia esos territorios ignotos. Un trabajo pionero de la década de los 60 fue el de Víctor Daniel Bonilla. ${ }^{5}$ En él analizó, por un lado, el proceso de ocupación de los territorios del valle de Sibundoy por parte de los capuchinos catalanes en las primeras décadas del siglo XX y, por otro, el desarrollo del proyecto misional capuchino entre las poblaciones indígenas del lugar.

Un trabajo más reciente sobre el papel de los misioneros en el proceso de colonización en el valle de Sibundoy es el de Augusto Javier Gómez López. ${ }^{6}$ Sobre el proyecto implementado por los misioneros capuchinos en el Caquetá

2 Pilar García Jordán, Cruz y arado, fusiles y discursos. La construcción de los Orientes en el Perú y Bolivia, 1820-1940 (Lima, Perú: Editora IFEA/IEP, 2001).

3 María Andrea Nicoletti, Indigenas y misioneros en la Patagonia: Huellas de los salesianos en la cultura y religiosidad de los pueblos originarios (Buenos Aires: Continente, 2008).

4 Pilar García Jordán, «Yo soy libre y no indio: soy guarayo». Para una historia de Guarayos, 1790-1948 (Lima, Perú: IFEA, PIEB, IRD y TEIAA, 2006).

5 Víctor Daniel Bonilla, Siervos de Dios y amos de indios. El Estado y la misión capuchina en el Putumayo (Cali, Colombia: Universidad del Cauca, 2006).

6 Augusto Javier Gómez López, «El Valle de Sibundoy: El despojo de una heredad. Los dispositivos ideológicos, disciplinarios y morales de la dominación», Anuario Colombiano de Historia Social y de la Cultura, n. 32 (2005): 51-73, https://revistas.unal.edu.co/index.php/achsc/article/view/8189. 
y Putumayo conviene señalar el trabajo de investigación de Misael Kuan Bahamón. ${ }^{7}$ Siempre sobre la región amazónica, ubicamos los trabajos de Gabriel Cabrera, quien se especializó en las misiones católicas y protestantes en el Vaupés colombiano y brasileño; ${ }^{8}$ y Jane Rausch, quien en un clásico trabajo analizó el papel que los misioneros desempeñaron en la incorporación material e ideológica de los Llanos Orientales al Estado nación colombiano. ${ }^{9}$

Si nos desplazamos a la región noroccidental, destacamos la tesis doctoral de la antropóloga Aída Gálvez Abadía. En ella analizó el proyecto misional de los carmelitas descalzos en la región de Urabá desde la perspectiva de la socialización de los sufrimientos de los misioneros..$^{10}$ Por otro lado, Juan Felipe Córdoba-Restrepo, en su trabajo de investigación doctoral, realizó un análisis comparativo entre el desarrollo de la actividad misional de los capuchinos que operaron en el Vicariato apostólico de la Guajira, Sierra Nevada y Motilones entre 1905 y 1952, y el de los carmelitas descalzos que operaron en la prefectura apostólica de Urabá entre 1918 y 1941. El objetivo del autor fue analizar el trabajo que desempeñaron los misioneros, entendidos como a intermediadores culturales, que mediante su encuentro con los lugareños proporcionarían un conjunto de modificaciones en las culturas locales. ${ }^{11}$ Por otro lado, si bien el trabajo de Claudia Steiner ${ }^{12}$ se centra en la naturaleza del proceso colonizador antioqueño en Urabá, dedica buena parte de la obra a indagar el papel que jugaron los carmelitas descalzos en dicho proceso.

En estos trabajos que acabamos de citar, especialmente los que abordan la problemática para el caso colombiano, echamos en falta un análisis que plantee la manera cómo se configuraron las miradas sobre las poblaciones indígenas de esos espacios de frontera y, especialmente, las miradas construidas por los misioneros. Esta problemática ha sido abordada por diversos investigadores e investigadoras en distintas regiones de América Latina. ${ }^{13}$ Para el caso colombiano,

7 Misael Kuan Bahamón, «La misión capuchina en el Caquetá y el Putumayo 1893-1929» (Tesis de Maestría, Pontificia Universidad Javeriana, 2013).

8 Cabrera Becerra, La Iglesia en la frontera: misiones católicas en el Vaupés, 1850-1950 (Bogotá, Colombia: Unibiblos, 2002); Gabriel Cabrera Becerra, Los poderes en la frontera. Misiones católicas y protestantes, y Estados en el Vaupés colombo-brasileño, 1923-1938 (Medellín, Colombia: Universidad Nacional de Colombia, 2015).

9 Jane Rausch, La frontera de los llanos en la historia de Colombia (1830-1930) (Bogotá, Colombia: Banco de la República, 1999)

10 Aida Cecilia Gálvez Abadía, Por obligación de conciencia. Los misioneros del Carmen Descalzo en Urabá Gabriel (Colombia), 1918-1941 (Bogotá, Colombia: Instituto Colombiano de Antropología e Historia, 2006).

11 Juan Felipe Córdoba Restrepo, «En tierras paganas Misiones católicas en Urabá y en La Guajira, Colombia, 1892-1952» (Tesis Doctoral, Universidad Nacional de Colombia, 2012).

12 Claudia Steiner, Imaginación y poder. El encuentro del interior con la costa en Urabá, 1900-1960 (Medellín, Colombia: Editorial Universidad de Antioquia, 2000).

13 Algunos de estos trabajos los podemos encontrar en: Pilar García Jordán, (ed.), El mundo latinoamericano como representación, siglos XIX-XX (Barcelona, España: Publicacions i Edicions UB /TEIA/IFEA, 2015) y Pilar García Jordán (ed.), La reinvención de América. Proyecciones y percepciones Europa-América Latina, siglos XIX-XX (Barcelona, España: Publicacions i Edicions UB /TEIA/ IFEA, 2017). 
Amada Carolina Pérez Benavides ${ }^{14}$ ha trabajado sobre cuáles fueron las representaciones que se construyeron sobre los pobladores de la nación producidas alrededor del Museo Nacional, de los impresos ilustrados y también de las misiones. Este último aspecto es abordado mediante el análisis de los informes elaborados en referencia a la región de los Llanos Orientales; los informes de misión publicados en la Semana Religiosa de Popayán y los informes de misión elaborados por los padres capuchinos sobre el Caquetá y el Putumayo. El análisis de estas fuentes permitió a la autora ver cómo fueron las representaciones elaboradas desde los márgenes de la nación -comparándolas con las producidas en los otros ámbitos abarcados en la investigación- por los misioneros. Ello le permitió llegar a la conclusión de que mediante estas publicaciones se pudo matizar y complejizar la representación construida, homogénea, de los pueblos indígenas de las selvas como a «tribus errantes». Estos escritos permitieron visibilizar la gran variedad de grupos indígenas que habitaban las distintas regiones del territorio nacional, también conocer sus particularidades y, como se denominaba en la época, «grados de civilización». Tomando como punto de partida esta propuesta analítica, con este trabajo queremos indagar sobre cómo fueron las representaciones construidas por los misioneros carmelitas descalzos de los gunadule ${ }^{15}$ del Darién colombiano.

La región del Darién fue uno de estos territorios ignotos sobre los que se debía emprender una tarea colonizadora para incorporarlo al cuerpo del Estado nación. Este territorio estaba poblado por diversos grupos indígenas, el pueblo gunadule es uno de ellos. Se asentaban en la parte alta de los valles del Bayano y Chucunaque, en San Blas, territorio costero ubicado entre Cabo Tiburón y la Bahía de Mandinga, territorios que hoy pertenecen a Panamá. En Colombia estaban establecidos en la región del golfo de Urabá, concretamente en la costa occidental y en Caimán Nuevo, en la costa oriental.

A pesar de que el pueblo gunadule es, quizás, uno de los pueblos originarios más estudiado, especialmente desde la antropología, son escasas las investigaciones que profundizan en el proceso del avance estatal, a través de las misiones católicas, sobre sus territorios. De los gunadule del lado panameño, el trabajo más significativo es el de Howe, ${ }^{16}$ el cual abarca los primeros 25 años del siglo XX. En él podemos observar los intentos del nuevo Estado por hacerse con el control de ese territorio fronterizo con Colombia. Al mismo

14 Amada Carolina Pérez Benavides, Nosotros y los otros. Las representaciones de la nación y sus habitantes. Colombia, 1880-1910 (Bogotá, Colombia: Editorial Pontificia Universidad Javeriana, 2015).

15 Los misioneros carmelitas descalzos denominaban a los gunadule con otro nombre. Para los religiosos eran los kuna o los indios caribes. En este trabajo utilizamos el término gunadule, pues es el que este pueblo decidió utilizar en el Congreso General de la Nación Kuna Tule de 2011 y que, desde el año 2010, llevan utilizando en Panamá.

16 James Howe, Un pueblo que no se arrodillaba. Panamá, los Estados Unidos y los kunas de San Blas (Miami, Estados Unidos de América: Plumsock Mesoamerican Studies; Centro de Investigaciones Regionales de Mesoamérica, 2004). 
tiempo, Howe fue abordando las resistencias que dicho pueblo ofreció a este avance estatal. Este interesante trabajo finaliza en el año 1925, por lo que todo el período posterior a la revolución tule de 1925, iniciado con la llegada de nuevos misioneros de la orden de los claretianos a las costas de San Blas, no ha sido prácticamente estudiado.

En el lado colombiano, aunque existió un esfuerzo destacado para incorporar esa región noroccidental colombiana y a sus habitantes al cuerpo de la nación, las investigaciones que trabajan esa marcha estatal a través de las misiones han sido escasas. Uno de los trabajos más completos sobre el proceso de ocupación y colonización del Darién Colombiano por parte del Estado en los siglos XIX y XX es la obra de Luís Fernando González Escobar. ${ }^{17}$ A lo largo de dos volúmenes el autor hace un análisis exhaustivo de los diversos proyectos implementados para eliminar las fronteras internas, llevar la «civilización» y el «progreso»a esa región para, así, transformar esos «desiertos» en campos productivos, bien comunicados y con modernos núcleos de población.

Sabemos que una de las estrategias implementadas por el Estado para lograr la colonización de esos espacios fue encargar a distintas órdenes religiosas emprender la tarea de facilitar la penetración del Estado y «civilizar» a sus habitantes, los gunadule. Los primeros intentos fueron emprendidos desde la región del Chocó por los hermanos capuchinos (1892-1899) y por los padres claretianos (1909-1918). Posteriormente, el cuatro de marzo de 1918 se levantó la prefectura apostólica de Urabá (1918-1941) encomendada a los padres carmelitas descalzos de la provincia de San Joaquín de Navarra, España, con el objetivo de centrar su atención en la zona del golfo de Urabá.

Por ese entonces, el área de ocupación del pueblo gunadule en la región del golfo de Urabá había ido menguando, progresivamente, a raíz del avance de nuevos colonos cuyo objetivo era implementar una dinámica económica capitalista en la región. De este modo, se empezaron a adentrar en el territorio cuadrillas de caucheros y tagüeros, con el fin de explotar estos preciados materiales y comercializarlos a través del puerto de Cartagena, principalmente. Ante esta avanzada, los gunadule se vieron obligados a abandonar sus lugares de asentamiento en las costas del golfo y desplazarse hacia el interior del Darién y a las costas de San Blas.

Tenemos conocimiento, gracias a un censo levantado por el cacique William Smith -Guillermo Oquelele- el día 1 de marzo de 1918, de que, en la región occidental del golfo de Urabá, en el Darién colombiano, vivían 328 miembros del pueblo gunadule. ${ }^{18}$ Un total de 226 hombres y 102 mujeres que

17 Luís Fernando González Escobar, El Darién. Ocupación, poblamiento y transformación ambiental. Una revisión histórica. Parte II (Medellín, Colombia: Instituto Tecnológico Metropolitano, 2012).

18 Archivo General de la Nación de Colombia - en adelante AGN-, «Resguardos indígenas de Toló y sus agregaciones en la Provincia del Darién», Intendencia del Chocó, Co.AGN.Ao/100.Mgob[2]-3//1.1.2 
se distribuían en las siguientes parcialidades: Cacicazgo del Tolo: 42 habitantes; Capitanía del Tigre: 21; Capitanía de Tanela: 34; Capitanía de Arquía: 85; Capitanía de Cuti: 112 y Capitanía de Cuque: 34 .

Por otro lado, en la región oriental del golfo, tan solo existía un asentamiento de este pueblo en la región de Caimán Nuevo. Según un censo que hemos localizado, levantado por la misma comunidad, en el año 1920 la población gunadule ascendía a 350 personas y, para el año 1939, 380. ${ }^{19}$

Los misioneros, para lograr el objetivo de convertir a los paganos indígenas al catolicismo y transformarlos en ciudadanos de la nación, debían implementar un conjunto de prácticas entre las que destacó la educación de los niños y niñas. Pero, en el desarrollo del proyecto misional, se ejecutaron otras. Una de ellas fue la propaganda misional que, a través de distintas publicaciones, pretendía captar fondos para el desarrollo de sus actividades apostólicas y, al mismo tiempo, despertar vocaciones entre sus lectores para aumentar el ejército de misioneros. ${ }^{20}$

A través de estas prácticas, los misioneros debían «civilizar» homogéneamente, estandarizar cultural y socialmente al pueblo gunadule, pues era una sociedad que, según ellos, pertenecían a tiempos premodernos, eran remanentes del pasado de la humanidad. Con ello se debía lograr, por un lado, incorporar a estos sujetos al tiempo de la «modernidad»y, por otro, transformarlos en verdaderos ciudadanos patriotas de la nación colombiana.

Pero, como veremos, los misioneros carmelitas descalzos, a través de sus discursos y fotografías no estaban contribuyendo del todo a ello, más bien estaban construyendo a unos «otros internos» con base en distinciones culturales. Esta ambivalencia entre un proyecto homogeneizador y otro diferenciador encaja con las corrientes teóricas que consideran que la nación es una construcción discursiva que no busca una homogeneización efectiva, sino la creación de patrones de normalización y jerarquización, a través de los cuales los distintos proyectos nacionales no buscaban negar y suprimir las diferencias de la heterogeneidad interior sino, más bien, producir y escenificar una idea determinada de los distintos pueblos y de sus diferencias. ${ }^{21}$

Por tanto, coincidimos con Peter Wade en que, para comprender las complejas realidades de los países de América Latina, es necesario alinearse con esta forma de entender la nación. Alejarse del paradigma de que la homogeneidad cultural total es la vía para la construcción de las naciones, pues esta no permite entender cómo la

19 AGN, «Comunidad Indígena de Caimán Nuevo». Turbo, Antioquia, Co.AGN.Ao/100.MGOB[2]-3//4.1.1

20 Un trabajo que aborda la propaganda misionera como un modo de captar fondos y vocaciones a través de las revistas es el de Aída Cecilia Gálvez Abadía, «Una limosna, caro lector”: la propaganda misionera de los Carmelitas Descalzos de Urabá, Antioquia». Boletín Cultural y Bibliográfico, vol. 49, nº 89 (2015): 25-45, https://publicaciones.banrepcultural.org/index.php/boletin_cultural/article/view/7526.

21 Santiago Castro-Gómez y Eduardo Restrepo, «Introducción: Colombianidad, población y diferencia», en: Genealogías de la colombianidad. Formaciones discursivas y tecnológicas de gobierno en los siglos XIX y XX, (ed.) Santiago Castro-Gómez y Eduardo Restrepo (Bogotá, Colombia: Editorial Pontificia Universidad Javeriana; Instituto de Estudios Sociales y Culturales Pensar, 2008), 21-22. 
heterogeneidad ha sido producida como un acto necesario para marcar unas jerarquías dentro de la nación y, por tanto, se estaría «soslayando la paradoja central de que una homogeneidad total implicaría erradicar cosas que las élites nacionales buscaban mantener -diferencias internas de clase, raza o región- $\rightarrow .^{22}$

Partiendo de esta base, los misioneros, a partir de diferencias de tipo étnico, racial, religioso, etc., estaban proveyendo «medios que habilitaban o disputaban modos diferenciados de explotación económica y de incorporación política e ideológica de una fuerza de trabajo - menos que de una ciudadanía- que se presuponía y re-creaba diferenciada». ${ }^{23}$ El punto, según Claudia Briones, es analizar cómo desde el Estado, desde poderes regionales o, en nuestro caso, a través de los misioneros carmelitas descalzos «se reproducen las desigualdades internas -y renuevan consensos en torno a ellas-invisibilizando ciertas divergencias y tematizando otras, esto es, fijando umbrales de uniformidad y alteridad que permiten clasificar a dispares contingentes en un continuum que va de "inapropiados inaceptables" a "subordinados tolerables" $\gg .{ }^{24}$ Es precisamente este el objetivo marcado en esta investigación, analizar cómo, mediante las representaciones que los misioneros carmelitas descalzos realizaron sobre el pueblo gunadule, establecieron una jerarquización, basada en aspectos de su cultura, que facilitarían su inclusión al cuerpo de la nación, pero de forma subalterna como a unos «otros internos».

Vamos a utilizar, para ello, fundamentalmente, la revista La Obra Máxima editada en España. ${ }^{25}$ Nuestro foco de atención no estará en el discurso elaborado a través de la palabra escrita, sino, en el discurso que construyeron mediante las fotografías que en ella incorporaron, ya que fueron un elemento indispensable de la revista, una forma de captar la atención del público lector ofreciéndole la posibilidad de ver, con sus propios ojos, los paisajes por donde misionaban los religiosos y los «indios salvajes» que debían «civilizar». Así lo apuntó el director de esta revista, fray Bernardino del Niño Jesús cuando le pidió al prefecto apostólico de Urabá, Severino de Santa Teresa, que le enviase

22 Peter Wade, Música, raza y nación. Música tropical en Colombia (Bogotá, Colombia: Vicepresidencia de la República de Colombia; Departamento Nacional de Planeación; Programa Plan Caribe, 2002), 5.

23 Claudia Briones, Cartografias argentinas. Politicas indigenistas y formaciones provinciales de alteridad (Buenos Aires, Argentina: Antropofagia, 2005), 15-16.

24 Ibíd., 16.

25 La revista La Obra Máxima es una publicación que se empezó a editar el año 1921 por los carmelitas descalzos de la Provincia de San Joaquín de Navarra, España. Esta revista tenía como objetivo sumarse a las publicaciones ya existentes sobre propaganda misional para dar a conocer las labores que los misioneros carmelitas descalzos realizaban en países extranjeros, además de ser un medio para obtener ayudas a la causa. La Obra Máxima todavía sigue editándose en la actualidad, pero nosotros, únicamente, analizaremos las publicaciones comprendidas entre el año 1921 y el 1950. Durante esta época la revista fue publicada mensualmente con aproximadamente 20 páginas por número. Se editaba en papel de prensa a blanco y negro, con ilustraciones -fotografías-y portada bicolor en cartulina. 
«relaciones y fotos de indios, etc. Cuanto más mejor. Gustan horrores a la gente y hay que animarla de esta forma». ${ }^{26}$

La relación de la fotografía con los procesos de evangelización llevados a cabo por misioneros ha sido trabajada por diversas investigaciones en distintas regiones de América Latina. A modo de ejemplo, Jaime Flores Chávez y Alonso Azócar Avendaño ${ }^{27}$ lo hicieron con el proceso «civilizador» de los misioneros capuchinos entre los mapuches en la región de la Araucanía en Chile; Pilar García Jordán con los franciscanos entre los guarayos en Bolivia y, Amada Carolina Pérez Benavides, utilizando las fotografías publicadas en distintos informes de misión y revistas de propaganda misional, se centró en el análisis de las fotografías tomadas por los hermanos capuchinos de las poblaciones indígenas del Valle del Sibundoy en la Amazonía colombiana. ${ }^{28}$

A través de las fotografías, los misioneros, por un lado, quisieron «mostrar» los logros obtenidos mediante la implementación de un proyecto determinado y, por otro, iluminar «aquellos aspectos que el productor de imágenes -en este caso el que las "encarga" - nos quiere transmitir a través de una determinada pose, de una escena, de una representación»». ${ }^{29}$

En estas capturas de momentos concretos del desarrollo de la actividad misional, los religiosos estaban otorgando un significado específico a su accionar $\mathrm{y}$, al mismo tiempo, transmitían una visión determinada de los pueblos indígenas

26 «Carta de fray Bernardino del Niño Jesús dirigida al padre Severino de Santa Teresa», San Sebastián (España), 16/11/1941, Fundación Sancho el Sabio, Archivo de la Prefectura apostólica de Urabá -en adelante FSS-APAU-, Prefectura de Urabá, caja 3, núm. 1.

27 Jaime Flores Chávez y Alonso Azócar Avendaño, «Rulpachen ka wigkachen pu Mapuche» Az nentulelu pu kapuchinu patiru Mapuche Mapu Mew/ «Evangelizar, civilizar y chilenizar a los Mapuches» Fotografias de la acción de los misioneros capuchinos en la Araucanía (Sevilla, España: Editorial Universidad de Sevilla/Ediciones Universidad de la Frontera, 2017).

28 Existen otros trabajos que abordan esa problemática, por ejemplo, ver: Alonso Azocar-Avendaño, Luis Nitrihual-Valdebenito, y Jaime Flores-Chávez, «La Patagonia en postales fotográficas: Misioneros salesianos y construcción de imaginarios sobre selk`nam, Kaweskar y yámanas entre 1880 y $1920 »$, Arte, Individuo y Sociedad vol. 25, n. ${ }^{\circ} 2$ (13 de mayo, 2013): 271-288, https://doi.org/10.5209/rev_ARIS.2013. v25.n2.39040; Pilar García Jordán, «Los Chiriguanos en la Esposizione d’Arte Sacra e delle Missioni e delle Opere Catoliche en Turín, 1898», en: El mundo latinoamericano como representación, siglos XIX$X X$, (ed.) Pilar García Jordán (Barcelona, España: Publicacions i Edicions UB /TEIA/IFEA, 2015), 99100; Gabriel Cabrera Becerra, «La fotografía de misiones y los indígenas del Alto Río Negro-Vaupés de Colombia y Brasil (1914-1965)», História Unisinos vol. 22, n 1 (enero-abril, 2018): 33-49, https:// doi.org/10.4013/htu.2018.221.03. Otros autores han trabajado utilizando la fotografía como un modo de análisis de las representaciones que distintos agentes, no solo religiosos, construyeron sobre poblaciones indígenas en América Latina: Patricia Alverenga Venutolo, Mauricio Menjívar Ochoa y María Esther Montanaro Mena, Miradas tramposas. Visiones antropológicas de viajeros por Centroamérica y México, siglo XIX y XX (San José, Costa Rica: EUCR, 2018); Anna Guiteras Mambiola y Pilar García Jordán, «El "otro" sirionó, objeto de la misión "civilizadora" del Núcleo Escolar Selvícola de Casarabe», en: $L a$ reinvención de América. Proyecciones y percepciones Europa-América Latina, siglos XIX-XX, (ed.) Pilar García Jordán, (Barcelona, España: Publicacions i Edicions UB /TEIA/ IFEA, 2017), 45-80.

29 Pilar García Jordán, Unas fotografias para dar a conocer al mundo la civilización de la república guaraya (Madrid, España: Consejo Superior de Investigaciones Científicas, 2009), 167. 
a quienes debían evangelizar y «civilizar»; estaban construyendo representaciones tanto de su actividad como de los habitantes del territorio.

Es necesario aclarar que compartimos la forma de entender las representaciones con quienes sostienen que estas no son una simple copia de la realidad, sino que son producidas mediante prácticas ${ }^{30}$ realizadas por sujetos que tienen unos intereses específicos y que apuntan a reconocer una identidad social, a exhibir una manera propia de ser en el mundo, a través de las cuales buscan imponer su autoridad y legitimar sus propios intereses. ${ }^{31}$

Partiendo de esta base, estas fotografías, supuestamente inocentes y objetivas, estaban conformando un discurso, a través del cual, los misioneros plasmaban su forma de entender el mundo y pretendían legitimar su actividad en esos territorios fronterizos de Colombia. Siendo esto así, con el análisis de las fotografías publicadas por los religiosos queremos desenmarañar las formas de mirar de estos religiosos sobre el pueblo gunadule y, cómo a través de estas, legitimaron su papel de «civilizadores» con base en la construcción diferenciada de un «otro» que, a partir de sus características culturales, les permitía edificar un entramado social jerarquizado donde, en la cima, se encontrarían los misioneros, como los representantes de la «civilización»y, en la base, los «indios salvajes» en su estado «natural».

Nuestra argumentación la vamos a dividir en dos partes. En la primera nos centraremos en la organización y el proyecto misional que implementaron los carmelitas descalzos en la Prefectura apostólica de Urabá para, finalmente, en la segunda, centrarnos en el análisis de las formas de representar al pueblo tule en las fotografías.

\section{La prefectura apostólica de Urabá (1918-1941)}

En el último tercio del siglo XIX, en el período denominado como regeneración, los dirigentes colombianos pensaron que sería más eficiente y productivo otorgar un papel protagonista a la Iglesia, mediante la instauración de misiones, en la tarea de ocupar los territorios «baldíos» y en la de «civilizar» a sus habitantes «salvajes». Para ello se construyó un nuevo marco político-institucional asentado en la Constitución de 1886, el Concordato firmado con el Vaticano en 1887, la Ley 89 de 1890 por la cual se determina la manera como deben ser gobernados los salvajes que vayan reduciéndose a la vida civilizada y la Ley 72 de 1892 por la cual se daban autorizaciones al Poder Ejecutivo para establecer misiones católicas.

Con la independencia de Panamá, en 1903, se conformó un nuevo límite internacional que, aunque no fuese reconocido oficialmente sino hasta 1924,

30 Las prácticas son modalidades de acción que se despliegan en un universo simbólico y social particular.

31 Roger Chartier, «Poderes y límites de la representación. Marin, el discurso y la imagen», en: Escribir las prácticas. Foucault, de Certeau, Marin, (ed.) Roger Chartier (Buenos Aires, Argentina: Manantial, 1996). 
requería la atención de Bogotá. Esta nueva coyuntura apresuró para que se conformara, en torno de los nuevos límites con Panamá, una nueva prefectura apostólica que, pese a que ya había sido proyectada en el Concordato con la Santa Sede el año 1887, no fue materializada hasta el año 1908, con la erección de la prefectura apostólica del Chocó, encomendada a los misioneros del Instituto de Hijos del Inmaculado Corazón de la Beatísima Virgen María, más comúnmente conocidos como claretianos. ${ }^{32}$ Estos religiosos debían lograr ocupar, colonizar, «civilizar» esos territorios y a sus poblaciones $\mathrm{y}$, al mismo tiempo, hacer ondear la bandera colombiana en los cielos y en los corazones de sus habitantes.

Ante la imposibilidad de atender correctamente los 75000 kilómetros cuadrados que conformaba la nueva prefectura, especialmente las regiones de la desembocadura del Atrato y del golfo de Urabá, por su lejanía de la capital misional, Quibdó, el $2^{\circ}$ prefecto apostólico, Francisco Gutiérrez, sugirió al nuncio apostólico reducir la extensión de la prefectura apostólica del Chocó y conformar una nueva que abarcase la región del golfo de Urabá y desembocaduras del Atrato. Este proyecto fue escuchado por el representante de la Santa Sede en Colombia y, el día 4 de marzo de 1918 se cristalizó mediante la creación, por parte de la Congregación de Propaganda Fide, de la prefectura apostólica de Urabá encomendada a los padres carmelitas descalzos de la provincia de San Joaquín de Navarra.

El territorio que abarcaría esta nueva jurisdicción fue:

[...] al norte el Golfo de Urabá desde el Promontorio de Arboletes hasta el Golfo de "La Miel», al Occidente los montes del Darién, por un filo, desde el dicho Golfo hasta el origen del río Napipí y el río Arquía hasta su origen; al Oriente desde el mencionado nacedero y atravesando por el río Murrí. ${ }^{33}$

\section{La organización territorial de la prefectura}

La implementación del proyecto misionero en el Urabá estaba lejos del modelo de reducción de los indígenas en poblados, pues adoptaron el modelo de evangelización itinerante, ya practicado por los claretianos en el Chocó. ${ }^{34}$ Este sistema consistía en establecer centros de Misión desde los cuales realizar excursiones apostólicas por el territorio que se le asignase a dicho centro misional; de este modo, los misioneros se irían ganando paulatinamente la confianza de las poblaciones indígenas para ir convenciéndolas de que modificasen sus formas de habitación, se fueran concentrando voluntariamente en poblados y, fueran

32 Para más información sobre la prefectura del Chocó ver David Díaz Baiges, «"Convertir para Dios y transformar para la patria". Misioneros claretianos y carmelitas descalzos entre los "indios errantes” del Chocó y Urabá, Colombia (1908-1952)» (Tesis de Doctorado, Universitat de Barcelona, 2018).

33 Decreto emanado de la Sagrada Congregación de Propaganda Fide sobre los límites geográficos de la prefectura apostólica de Urabá. Roma, 4/03/1918. FSS-APAU, prefectura de Urabá, caja 1, núm. 2.

34 David Díaz Baiges, «"Convertir para Dios y transformar para la patria”», 229-234. 
adoptando la «verdadera fe» para, de este modo, lograr «civilizarlas» y conducirlas hacia el «progreso»

La prefectura de Urabá fue dividida en dos distritos, uno en la región del sur o la zona de montaña y el otro en la región del norte o de la costa. A su vez, estos distritos eran divididos en cuasi-parroquias donde existía una estación misional y a las que se les delimitaba un territorio que debían administrar y por el que debían realizar las excursiones apostólicas correspondientes.

Además de la presencia fija del misionero en estas estaciones, también tenía la misión a disposición dos padres y un hermano misionero que visitaban constantemente los puntos más alejados de estos centros; lograban, en un año, visitar todos los caseríos de cierta importancia y a los indígenas dispersos en las orillas de los grandes ríos de Urabá. ${ }^{35}$

\section{El proyecto misional de los carmelitas descalzos en el Urabá}

A inicios de la prefectura, tres fueron los objetivos capitales que se marcaron los misioneros para llevar adelante la misión. Estos consistían en interinidad de la vida religiosa en los pueblos ya cristianos, reducción de «salvajes» y colonización. ${ }^{36}$

El primer punto tenía como función principal incorporar a las poblaciones cristianas a la vida religiosa mediante la integración de lo religioso en sus espacios. Por ello, era fundamental la construcción de iglesias o capillas por todo el territorio, para hacer efectiva la presencia del misionero en esos vastos territorios, pues, aunque por la falta de personal no hubiese religiosos de forma permanente en todos los pueblos y caseríos, ellos siempre estarían presentes representados en la cruz de los templos.

El segundo punto pretendía delimitar un territorio que se encontrase junto o dentro de territorio indígena. En él se debía construir: una casa hospital, botica, cooperativas o pequeños comercios donde se pudiera comprar lo necesario a precios módicos, sin utilidad para la misión. Proseguir la catequización de los indígenas por medio de las hermanas catequistas y enseñarles oficios manuales. Edificar, por cuenta de la misión, grupos de casas o habitaciones sencillas para las familias indígenas que voluntariamente las quisieran aceptar e iniciar así la vida «civilizada».

El objetivo del tercer punto era el de fomentar el desarrollo de las poblaciones «civilizadas» existentes y favorecer el surgimiento de nuevas. Por último, y no menos importante, tenían que atender la instrucción pública de la población.

35 Severino de Santa Teresa, «Informe de la prefectura apostólica de Urabá», Turbo (Colombia) 12 de octubre de 1932, FSS-APAU, prefectura de Urabá, caja 4, núm. 3.

36 «Informes sobre los límites de los municipios de la prefectura apostólica de Urabá, 1920/ 1924», FSS A.P.A.U. Prefectura de Urabá, caja 4, núm. 3. En las hojas finales del informe hay un documento que parece ser un borrador elaborado con la intención de justificar la redacción de una ordenanza que posibilitara y facilitara la ejecución de los tres puntos mencionados. 
La instrucción escolar fue el pilar sobre el que los misioneros fundamentaron su labor apostólica puesto que, como apuntaban, esta «sirve de poderoso auxiliar al Misionero para la moralización de esta región, pues la regeneración se debe empezar por la niñez». ${ }^{37}$

Teniendo en cuenta que los misioneros consideraban que la educación de los niños y niñas era el medio más eficaz para catequizar e instruir a los indígenas, no se demoraron en llevar a la práctica esas creencias. De este modo, con la llegada de los misioneros al golfo, el año 1920, lo primero que hizo el prefecto Arteaga fue establecer contacto con los gunadule de Caimán Nuevo, para pedirles permiso para construir una residencia y una escuela en sus territorios. Ante la negativa de esta comunidad y sabiendo el prefecto que, entre los gunadule del Darién tendría alguna posibilidad, gracias a los conocimientos que les transmitieron los claretianos, emprendieron la marcha hacia esa región. Tenían en mente establecer una escuela para los gunadule del Darién, por lo que obtuvieron, de la intendencia nacional del Chocó, el permiso para levantar una escuela en la localidad de Unguía. El mes de mayo de 1922 los misioneros, estando en Unguía para hacer los preparativos correspondientes, recibieron una carta del cacique Manuel Díaz Granados invitándolos a que lo visitasen. A partir de ese momento establecieron buenas relaciones y en el año 1932 consiguieron instalar una residencia y colegio en la localidad de Arquía donde se administraba educación a la niñez de todas las capitanías gunadule lideradas por el Cacique de Arquía, Tigre, Cuti, Cuqué, Tanela y Tolo -ver mapa 1-.

Posteriormente, el 9 de septiembre de $1934,{ }^{38}$ se inauguró un internado indígena en San José de Turbo para atender tanto a los gunadule como a los embera-catío. ${ }^{39}$ Con el fin de dar mayor expansión a este internado y complementarlo con una granja que sirviera para campos de experimentación y formación agrícola y, al mismo tiempo, con sus frutos, facilitar el sostenimiento de sus alumnos, se decidió trasladar el internado, pues los terrenos próximos a San José eran arenales estériles para las labores agrícolas. Este internado, que no solo sería para indígenas sino también para los otros habitantes de la región, los afrodescendientes, se trasladó a Río Grande, a unos 35 kilómetros al este del golfo de Urabá, a la vera del trazado de la carretera al mar y fue inaugurado a principios de noviembre de $1940 .{ }^{40}$

37 Severino de Santa Teresa, «Ecos de la Misión», Luz Católica, n. ${ }^{\circ}$ 19, año IV (1 de marzo de 1930): 74-75.

38 Editorial, «Notas regionales», Luz Católica, n. ${ }^{\circ} 18$ (176), año VIII (15 de septiembre de 1934): 72.

39 Para más información sobre el proyecto misional implementado con los embera-catío ver: David Díaz Baiges, «"Convertir para Dios y transformar para la patria"».

40 Santa Teresa, Historia documentada de la iglesia en Urabá y el Darién: desde el descubrimiento hasta nuestros días. Vol.5 Época de la América Española Independiente (1810-1956) (La prefectura apostólica de Urabá) (Bogotá, Colombia: Empresa Nacional de Publicaciones, 1956), 428. 
Mapa 1. Asentamientos dunagule en el golfo de Urabá durante la Prefectura Apostólica de Urabá

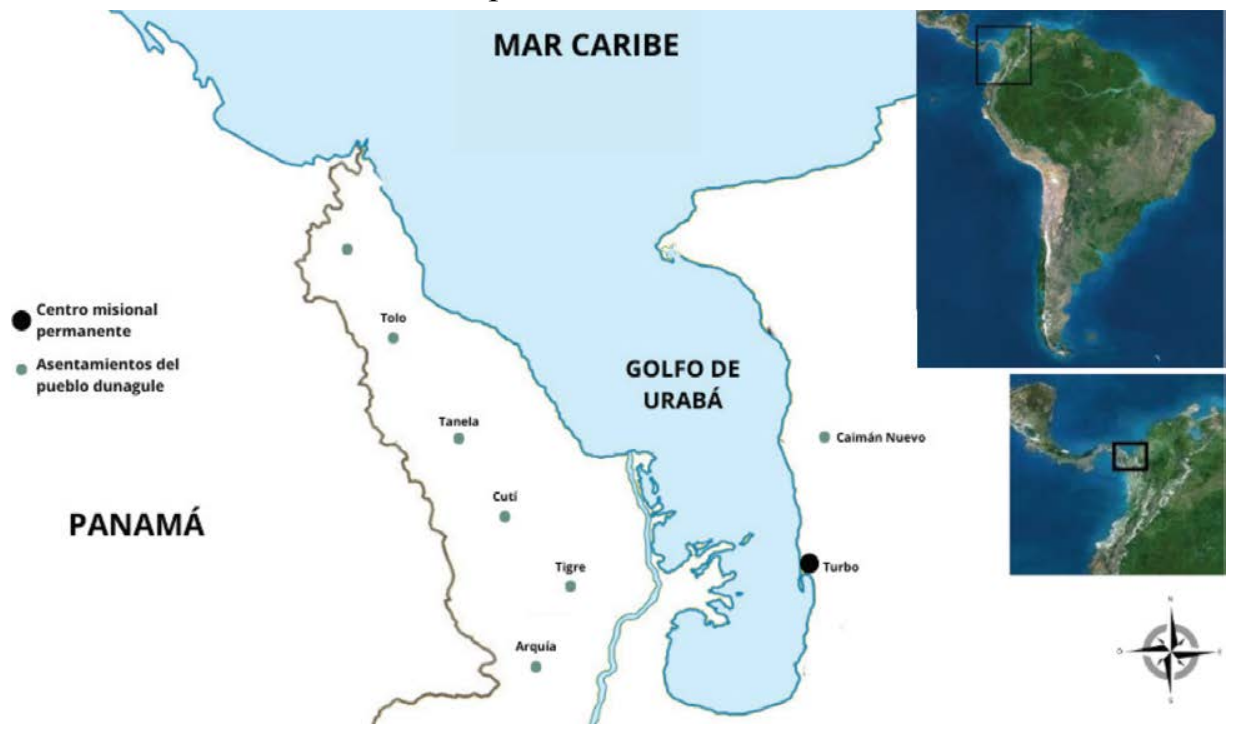

Fuente: Elaboración propia a partir de Severino de Santa Teresa, Historia documentada de la iglesia en Urabá y el Darién, 5, 713.

Los objetivos que pretendían lograr mediante la instrucción de los neófitos en estos centros escolares eran varios. Primero, debían favorecer el aprendizaje de la lengua castellana, la modificación de su forma de vestir ${ }^{41} \mathrm{y}$ el adoctrinamiento religioso pues, consideraban que estos eran los pasos iniciales para preparar al neófito para la vida «civilizada». Un segundo objetivo consistió en introducir entre los neófitos el amor incondicional a la patria, inculcando en los niños el sentimiento hacia la bandera tricolor y al himno nacional. En tercer lugar, los niños y niñas debían formarse en oficios y técnicas agrícolas para cooperar con la economía nacional. Los misioneros consideraron que esta última faceta era muy importante $\mathrm{y}$, es por eso por lo que optaron por construir el internado granja escuela donde se formaría a los indígenas y a los afrodescendientes de la región de Urabá en estas artes, con el fin de convertirlos en elementos productivos para la patria. ${ }^{42}$

41 Cierto es que la forma de vestir de los kunas no era cuestionada por los religiosos, incluso en algunos casos los misioneros consideraban particularmente bonitos los vestidos de las mujeres, pero consideraban que no eran adecuadas para el mundo civilizado. El vestido era la marca que identificaba a los indígenas en cuanto «semisalvajes» e «inferiores», motivo por el cual era el primer elemento que se debía eliminar de su forma de vida. Esta transformación de la forma de vestir estaba relacionada con el proceso de escolarización. Al igual que, como muestra Pérez Benavides con los indígenas del Putumayo, en las imágenes de los informes de los misioneros, los niños y niñas, cuando están en el ámbito escolar aparecen uniformados, en cambio cuando muestran a los indígenas fuera de dicho ámbito, los exhiben con sus trajes y adornos típicos. Más adelante tendremos ocasión de comentar la cuestión al analizar las fotografias publicadas por los misioneros. Amada Carolina Pérez Benavides, Nosotros y los otros...

42 Para más información sobre el proyecto misional de los carmelitas descalzos en la región de Urabá ver David Díaz Baiges, "“Convertir para Dios y transformar para la patria”», 252-274. 
Estas prácticas implementadas para lograr «civilizar» a los gunadule fueron descritas en numerosos textos que los religiosos difundieron a través de las revistas de propaganda misional o de los informes misionales que publicaron. Mediante estos, los misioneros construyeron una determinada imagen de este pueblo que los posicionaba, dentro de una supuesta escala jerárquica entre la «civilización» y el «salvajismo», en un lugar próximo a la «civilización». Fueron considerados por los religiosos como «el único consuelo del misionero». ${ }^{43}$ Diversos fueron los elementos de su cultura que los posicionaban en ese lugar: su gran laboriosidad, su amor a la familia y a los niños, sumisión, honradez, higiene, vestimentas, prácticas religiosas, respeto a la autoridad, orgullo e independencia y defensa del territorio. ${ }^{44}$ Ahora bien, estas prácticas también fueron registradas a través de las fotografias que los propios religiosos realizaban y, a través de ellas, también representaron a este pueblo. Es por ello por lo que en el próximo apartado vamos a analizar las representaciones que, en el devenir de la actividad misional, los carmelitas descalzos construyeron con las fotografias que publicaron, principalmente, en La Obra Máxima.

\section{Representaciones y fotografía}

En la revista La Obra Máxima, los misioneros carmelitas descalzos publicaron un importante volumen de fotografías que pretendían ofrecer a su público lector una «ventana» hacia los territorios de misión del Urabá. Las fotografías fueron muy variadas, desde las que capturaban paisajes selváticos o centros urbanos, hasta las que mostraban la cotidianeidad de las actividades de los religiosos. Buena parte de estas imágenes se centraron en plasmar al pueblo gunadule y las prácticas «civilizadoras» que emprendieron con este y, es precisamente, en estas fotografías en las que nos vamos a centrar. Utilizaremos, fundamentalmente, las publicadas

Figura 1. Grupo de indígenas gunadule de Arquía bajo árboles de cacao

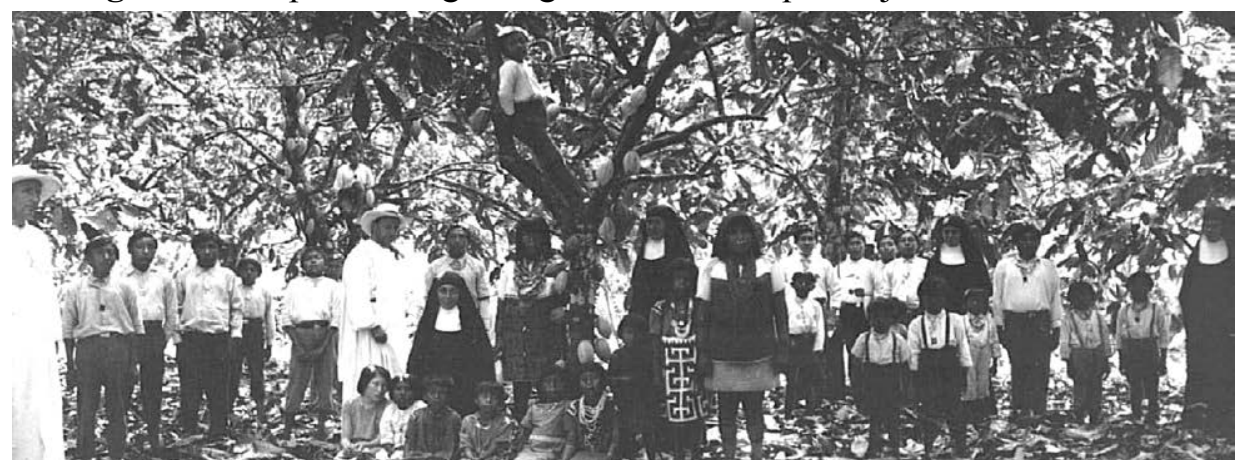

Fuente: FSS-APAU, Material gráfico, caja 9, núm. 3.

43 Editorial, «Urabá (América). Horizonte cerrado», El Siglo de las Misiones, n. ${ }^{\circ}$ 111, año X, (marzo de 1923): 80.

44 Para más información sobre las representaciones construidas sobre el pueblo tule véase David Díaz Baiges, «"Convertir para Dios y transformar para la patria”», 303-322. 
Figura 2. Pareja gunadule junto el padre Amancio de

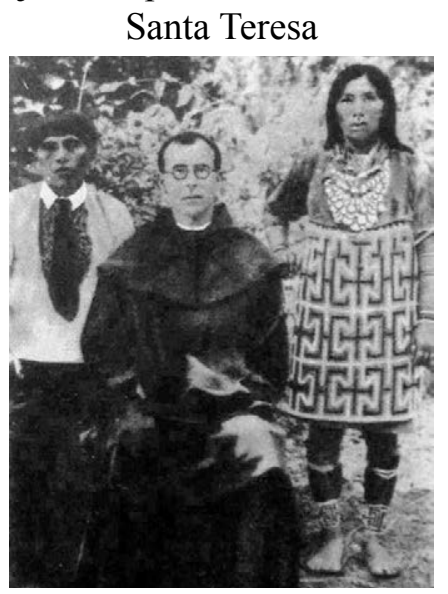

Fuente: La Obra Máxima, n. ${ }^{\circ}$ 150, junio de 1933, 171.

en la revista de propaganda misional antes citada $\mathrm{y}$, también, algunas que están depositadas en los fondos de la prefectura apostólica de Urabá del Archivo de la Fundación Sancho el Sabio y, de las que, en su mayoría, no conocemos ni fotógrafo ni fecha exacta en que fueron realizadas.

Ya vimos que para los carmelitas descalzos los gunadule eran el único consuelo del misionero $\mathrm{y}$, como tales, las representaciones que sobre ellos construyeron fueron positivas, caracterizándolos como a un pueblo que se encontraba en las puertas de la «civilización». Anteriormente nombramos los ingredientes que conformaban esa representación, veamos ahora cómo los representaron a través de la fotografía.

Un primer ingrediente, el carácter laborioso de este pueblo fue representado, por ejemplo, a través de la figura 1. En ella podemos distinguir a un conjunto de habitantes de Arquía, de todas las edades y sexos, posando bajo unos árboles de cacao. Esta plantación -con grandes árboles y frutos- tenía la funcionalidad de mostrar la potencialidad de este pueblo como productor de cacao y, consecuentemente, los beneficios económicos que supondrían su incorporación a la nación.

El amor a la familia es uno de los ingredientes que más se representó a través de las fotografías publicadas. En ellas se quiere dejar constancia de que en este pueblo la familia nuclear es la que predomina y, por ello, se retrataron a matrimonios con sus hijos o a parejas junto al misionero, ubicado en la parte central de la escena, quien estaría dando el visto bueno a esa unión. Ilustran esta afirmación las figuras 2 y 3 .

Figura 3. Cinco parejas gunadule preparadas para recibir el santo matrimonio

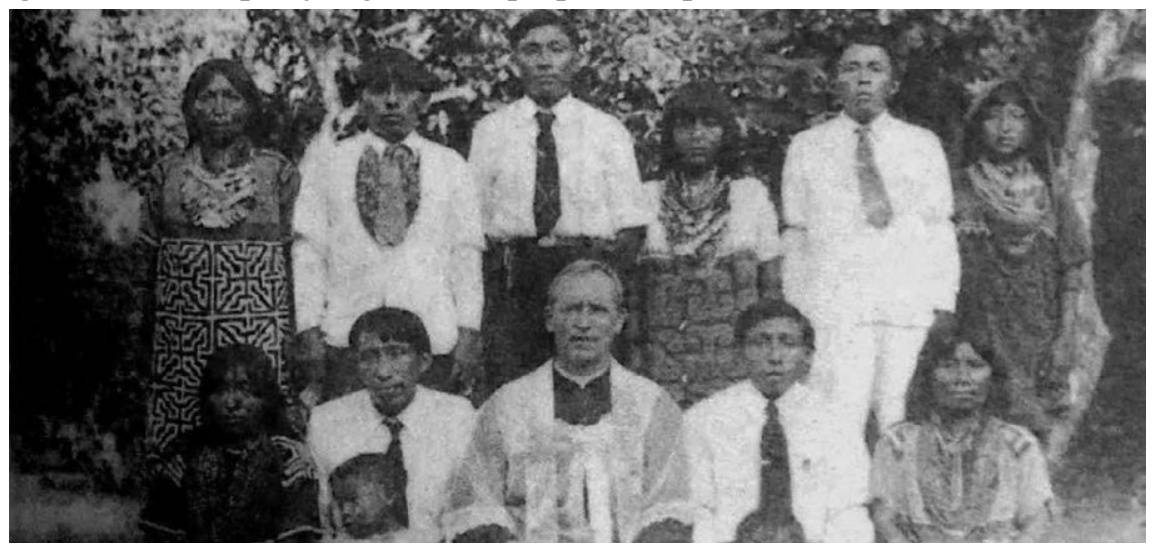

Fuente: La Obra Máxima, n. ${ }^{\circ}$ 313, mayo de 1947, 143. 
La forma de vestir de este pueblo fue otro de los ingredientes que componían esa representación positiva. En las fotografías 4, 5 y 6 observamos como retrataron a los hombres, vestidos con pantalón, camisa y, en ocasiones, con corbata, y a las niñas y mujeres con sus vestidos tradicionales o molas, atuendo que fascinó a los misioneros. A pesar de ello, en esta escenificación existían detalles que querían mostrar que este pueblo todavía tenía reminiscencias de «salvajismo». Esto lo podemos ver reflejado, por ejemplo, en el hecho de que los hombres, a pesar de ir vestidos «correctamente» todavía no utilizaban calzado, o que las niñas y mujeres continuasen utilizando sus vestimentas tradicionales que, aunque gustasen a los religiosos, no eran atuendos adecuados para la «civilización»y, desprenderse de ellas era esencial para acceder a ella. Otro elemento que destacar es el hecho de que el escenario de todas las imágenes se enmarcó en la selva, elemento que simbolizaba la pertenencia de este pueblo a ese ámbito «salvaje». La figura 6 es un ejemplo representativo, puesto que está mostrando el proceso de transición del pueblo gunadule desde un estado «salvaje» a uno «civilizado». La imagen nos muestra a un grupo de niñas que acaban de tomar su primera comunión, vestidas con sus molas y adornadas con las narigueras; al mismo tiempo todas ellas aparecen con el velo característico de un vestido de primera comunión y, en una de ellas podemos ver una medalla en forma de crucifijo. También observamos como la escenificación de esa primera toma del cuerpo de Cristo no fue en una iglesia o un escenario religiosos, sino que, de nuevo, fue en la selva.

Figura 4. Retratos de hombres y mujeres gunadule

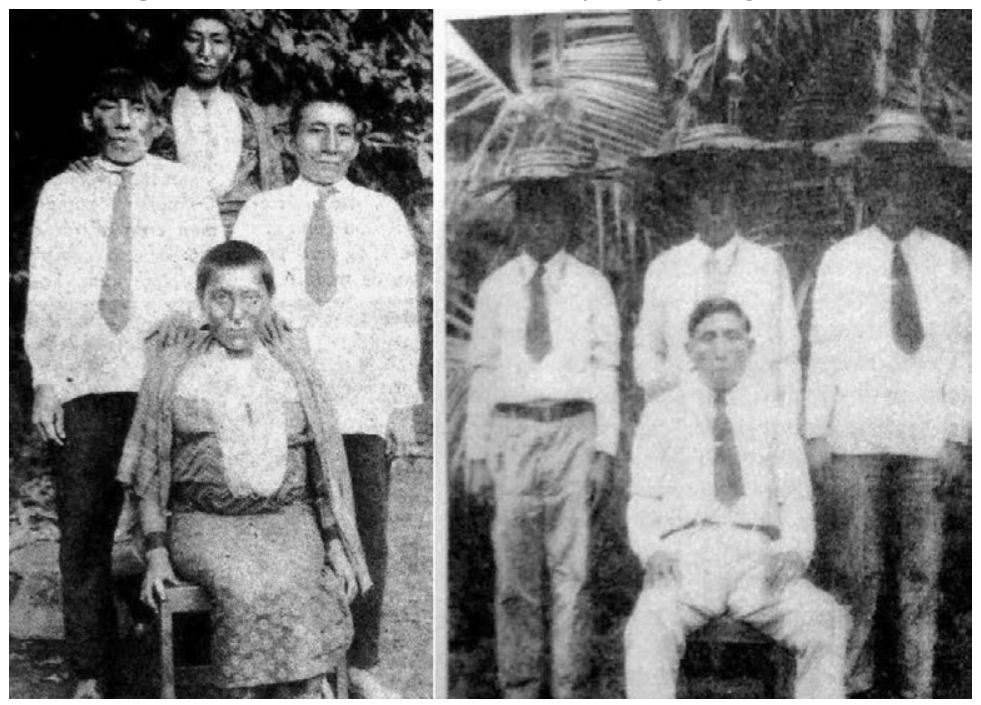

Fuente: Izquierda, La Obra Máxima, n. ${ }^{\circ}$ 319, noviembre de 1947, 331: Derecha, La Obra Máxi$m a$, n. $^{\circ} 289$, mayo de $1945,140$. 
Figura 5. Grupo de niñas gunadule de Arquía junto al padre misionero

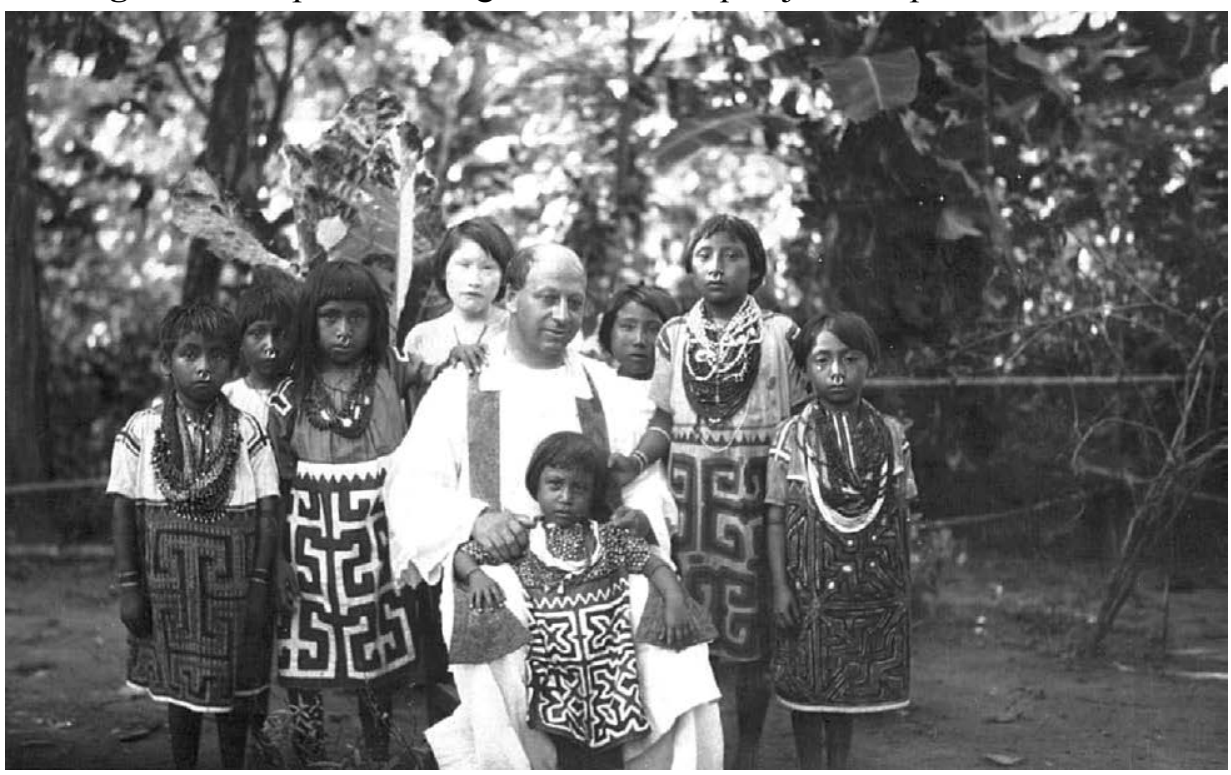

Fuente: FSS-APAU, Material gráfico, caj.9, núm. 3.

Figura 6. Grupo de niñas gunadule de Arquía celebrando la primera comunión

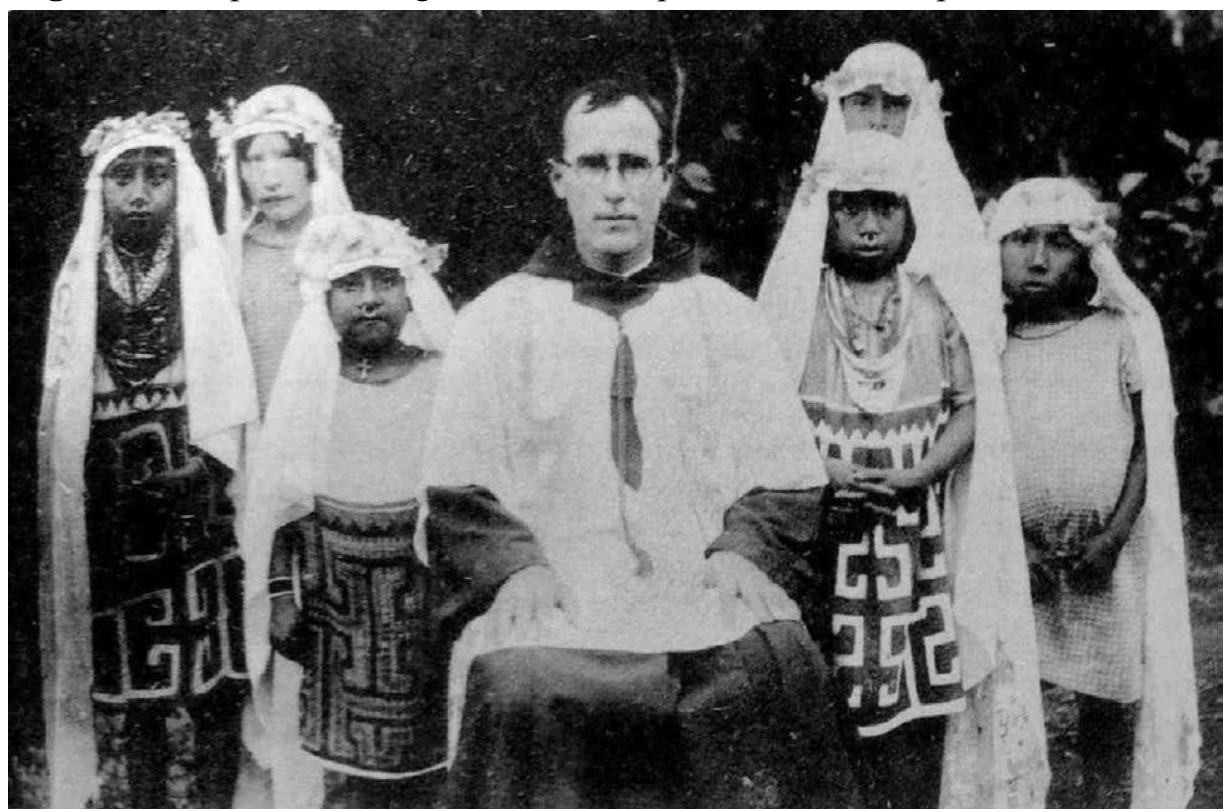

Fuente: La Obra Máxima, n. ${ }^{\circ}$ 159, marzo de 1934, 77. 
Los carmelitas descalzos hicieron un gran esfuerzo por registrar visualmente su tarea de convertir a los gunadule. Así, en Arquía, captaron escenas de niños y niñas en el recreo de la escuela -figura 7-o posando frente a la residencia del misionero, mientras aparentan estar esperando las instrucciones del religioso-figura 8-.

Figura 7. Niños y niñas gunadule de Arquía jugando durante el recreo

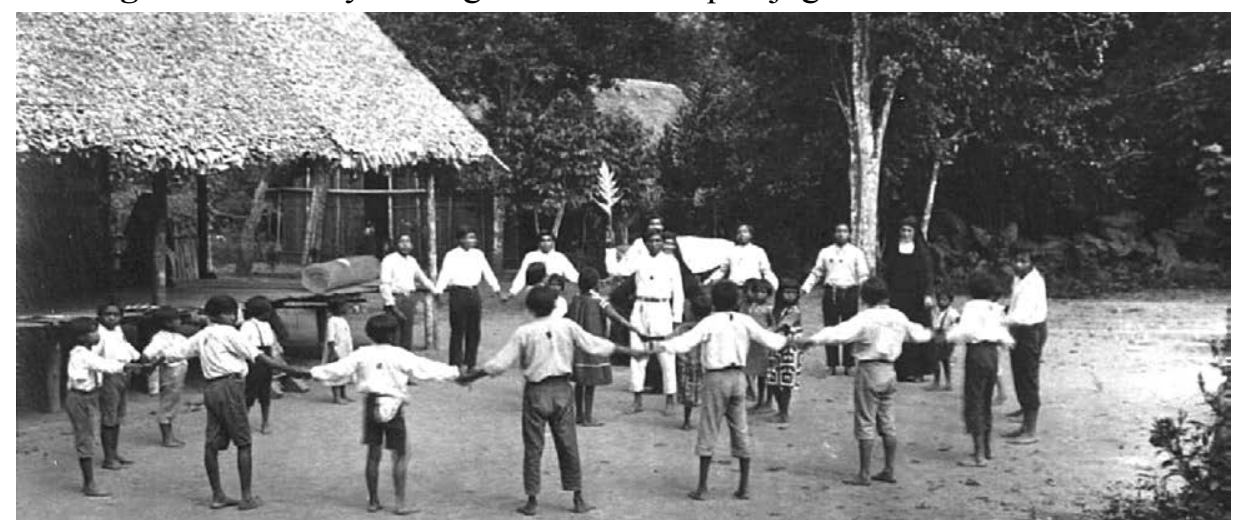

Fuente: FSS-APAU, Material gráfico, caj.9, núm. 3.

Con estas fotografías estaban representando, de nuevo, esa idea de que este pueblo era un buen candidato para acceder a la «civilización» pues, como vemos en la fotografía 8 , estaban dispuestos a seguir las enseñanzas.

También retrataron a los niños del internado de San José de Turbo. En esas fotografías se refleja que la labor conversora estaba teniendo éxito. Por último, en las fotografías 9 y 10 podemos ver otro de los ingredientes de las representaciones construidas sobre este pueblo. En la fotografía 10 se capturó el momento en que los caciques de Arquía y
Figura 8. Grupo de niños y niñas gunadule de Arquía frente a la residencia del misionero

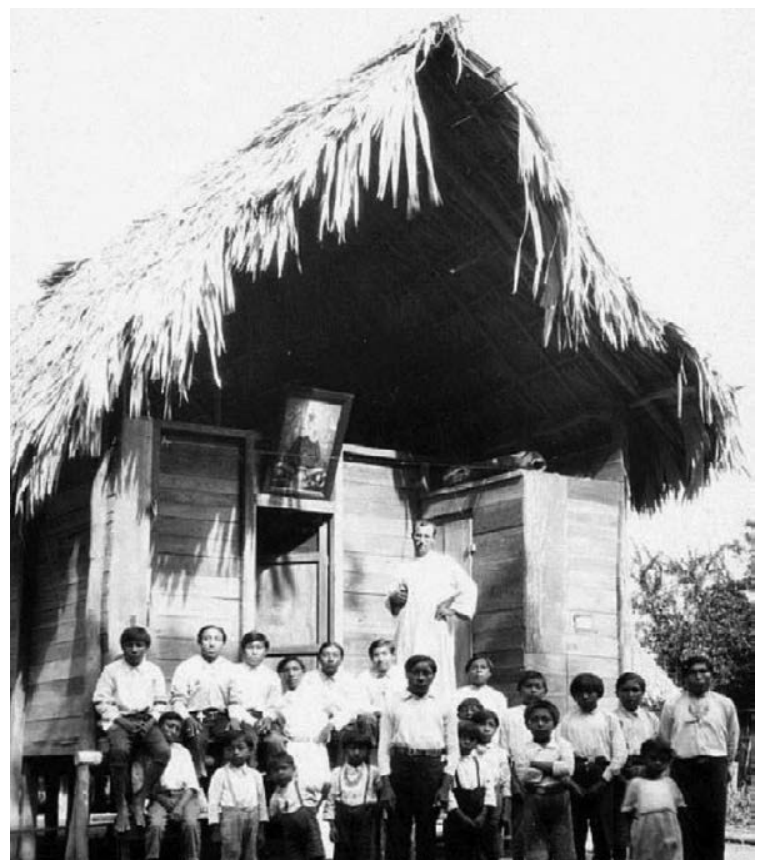

Fuente: FSS-APAU, Material gráfico, caj.9, núm. 3. 
Caimán Nuevo saludaban al prefecto apostólico en el marco del segundo congreso eucarístico de Medellín. En ella vemos representado el respeto a la autoridad de este pueblo frente al gobierno colombiano y frente a la misión. Esto está simbolizado en el hecho de que ambos caciques lucían una banda con la bandera colombiana, que esta bandera estuviera ondeando sobre el séquito del alumnado del internado de San José de Turbo que acompañaba a los caciques y, por el hecho de que estuvieran estrechando la mano al prefecto. A su vez, en la fotografía 9 se constata ese respeto a la autoridad cuando el cacique de Caimán Nuevo, Capilele, fue bautizado en un acto público por el arzobispo de Bogotá.

Figura 9. Bautizo de Capilele, cacique de Caimán Nuevo en acto oficial

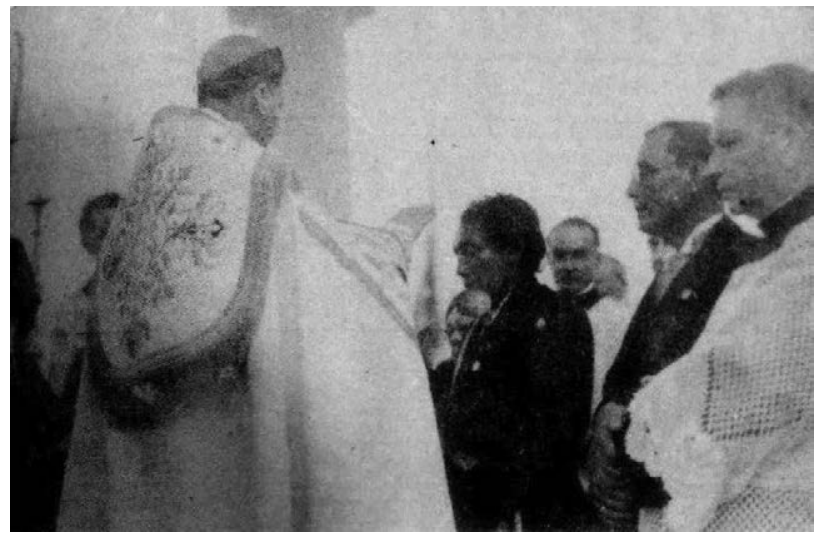

Fuente: La Obra Máxima, n. ${ }^{\circ}$ 228, abril de 1940, 57.

Figura 10. Los caciques de Caimán Nuevo y de Arquía en el Segundo Congreso Eucarístico de Medellín

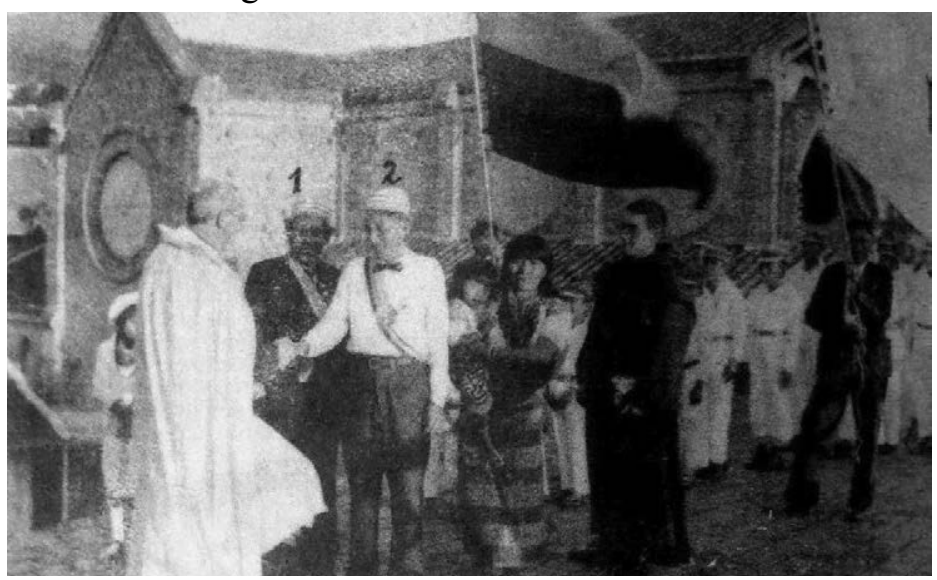

Fuente: La Obra Máxima, n. ${ }^{\circ}$ 188, agosto-diciembre de 1936, 232. 
Las fotografías que escenificaban las prácticas que llevaban a cabo para transformar a los neófitos fueron recurrentes. A partir del conjunto de fotografías consultadas podemos establecer tres tipografías distintas, unas que registraron el proceso de «civilización» mediante la instrucción escolar, otras mediante actividades religiosas y otras mediante actividades cívico-patrióticas.

Las capturas que querían representar la acción evangelizadora a través de la instrucción escolar fueron de dos tipos, unas que consistían en retratos grupales de los alumnos y alumnas de esas instituciones y otras que captaron momentos específicos de la actividad que en ellas se desarrollaban.

Del internado de San José de Turbo publicaron retratos grupales donde el misionero está ubicado en el centro de la imagen, vestido con sus hábitos y rodeado por el grupo de internos correctamente uniformados -ver fotografía 11-. Con este tipo de retratos se quería representar el triunfo de la labor misional a través de estos centros educativos y, la forma de simbolizarlo era con el abandono de los vestidos típicos de los neófitos.

El segundo tipo de fotografías son aquellas que captaron momentos específicos de la actividad «civilizadora» que se estaba desarrollando. Eran imágenes que pretendían representar la formación de individuos sanos, productivos y patriotas, quienes podrían servir de mano de obra para favorecer el progreso de la región o incluso que podrían ser útiles como fuerzas armadas para la defensa del territorio nacional. Ejemplos de ellos son las fotografías 7, 12 y 13. En ellas capturaron distintas actividades formativas con las que instruían a los alumnos y alumnas, generalmente, del internado de San José de Turbo. Estas querían dar cuenta de los progresos que estaban teniendo los neófitos en el aprendizaje de las letras, en valores religiosos y en praxis social.

Figura 11. Alumnos del colegio de San José de Turbo

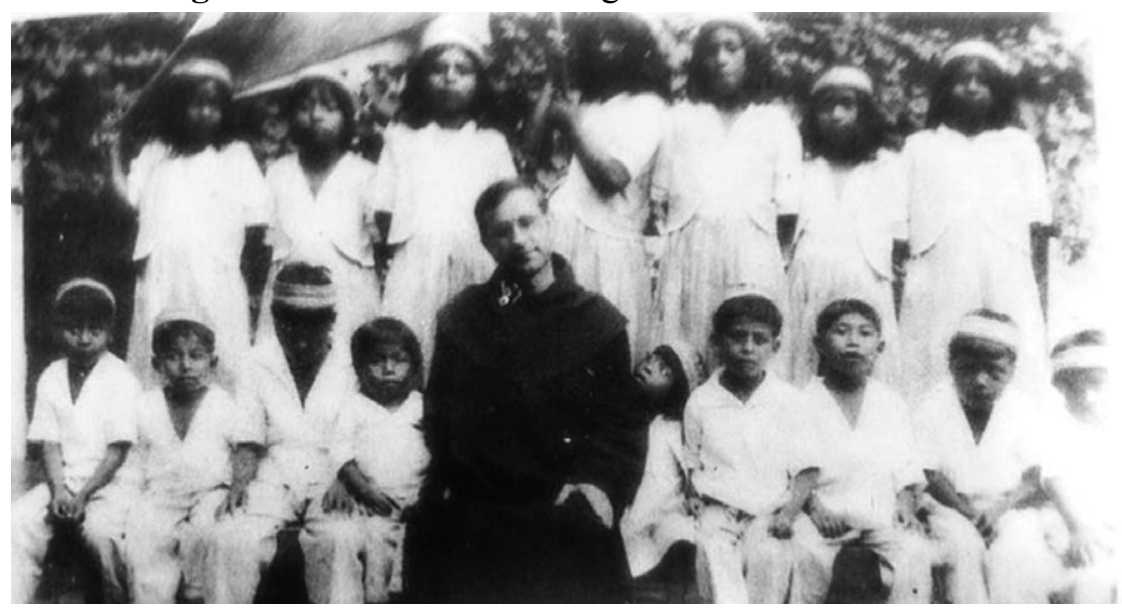

Fuente: La Obra Máxima, n. ${ }^{\circ}$ 252, abril de 1942, 57. 
Figura 12. Niños aprendiendo castellano junto a una hermana misionera

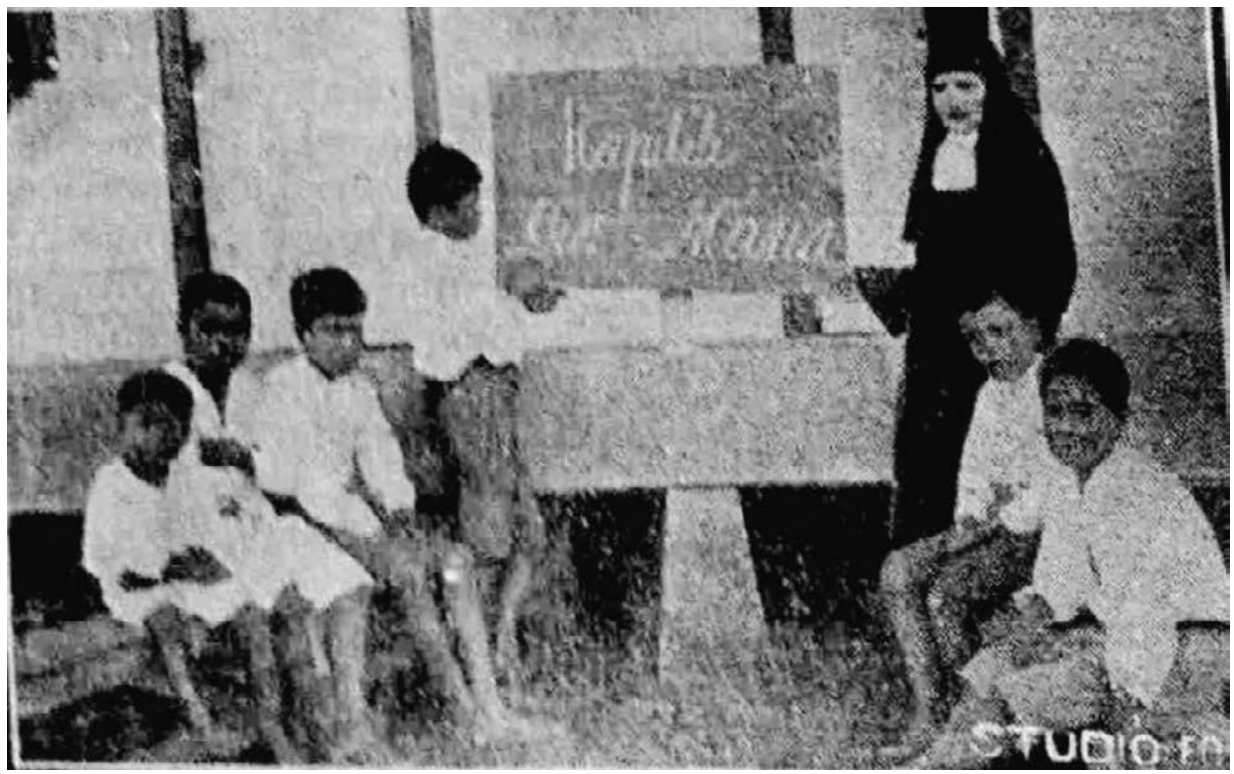

Fuente: La Obra Máxima, n. ${ }^{\circ} 111$, marzo de 1930, 72.

Figura 13. Internos de San José de Turbo posando ante sus camas

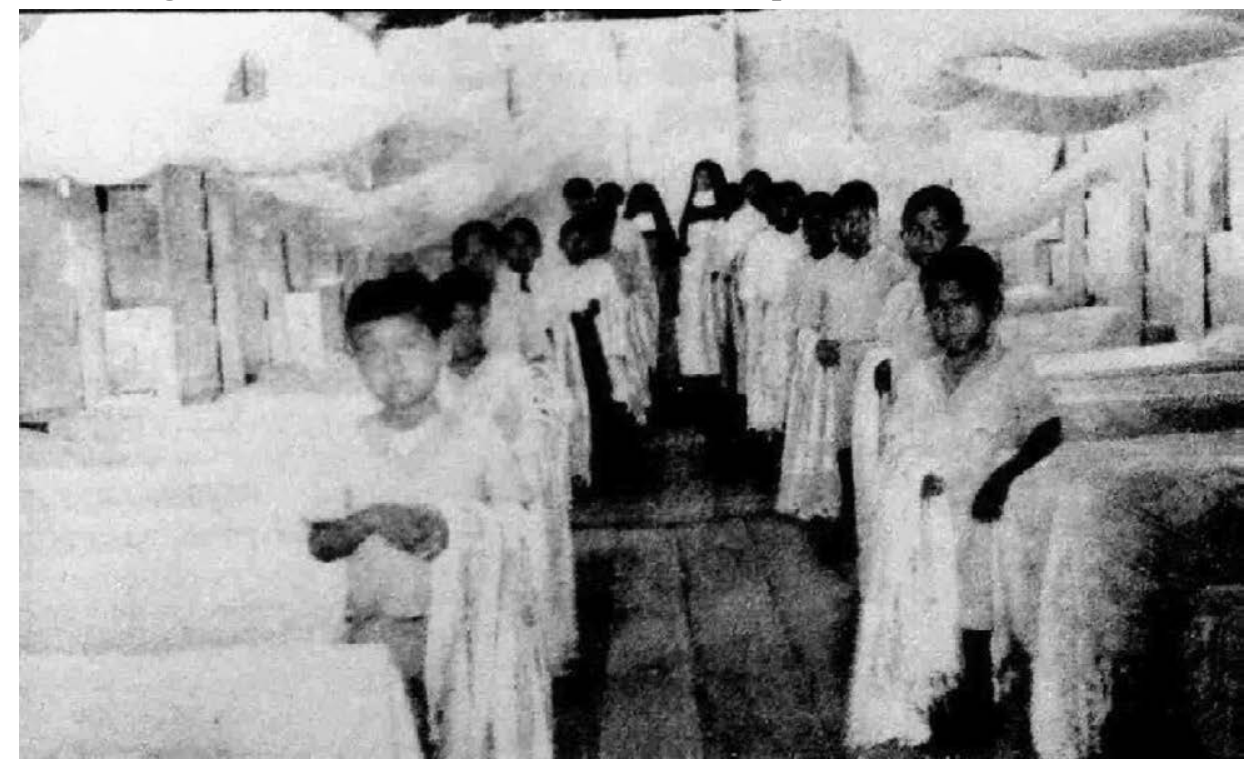

Fuente: La Obra Máxima, n. ${ }^{\circ}$ 198, octubre de 1937, 151. 
El proceso de instrucción en los oficios y en técnicas agrícolas modernas también fue representado a través de imágenes, aunque fueron escasas. En la fotografía 14 se observa un grupo de niños arreglando la lancha de la misión y, en la 15 , podemos observar cómo se instruía en técnicas agrícolas «modernas».

Figura 14. Niños del Internado de San José de Turbo reparando la lancha de la prefectura

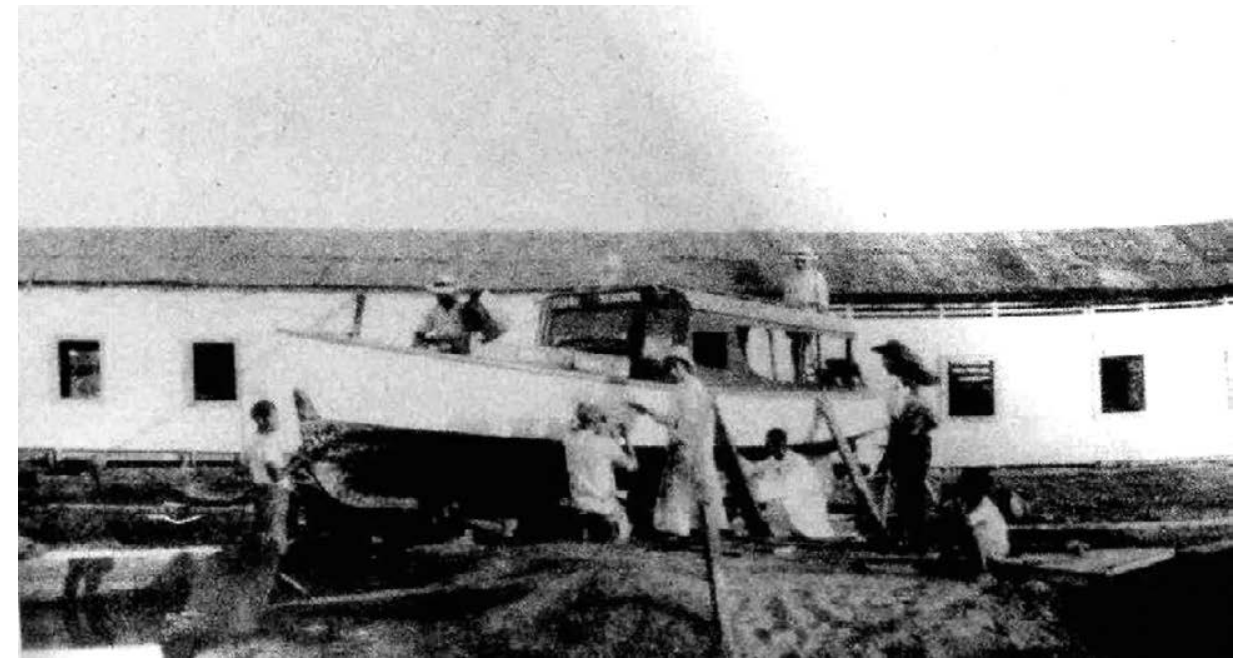

Fuente: La Obra Máxima, n. ${ }^{\text {2 } 221, ~ s e p t i e m b r e ~ d e ~ 1939, ~} 138$.

Figura 15. Niños y niñas tomando clases de agricultura «moderna»

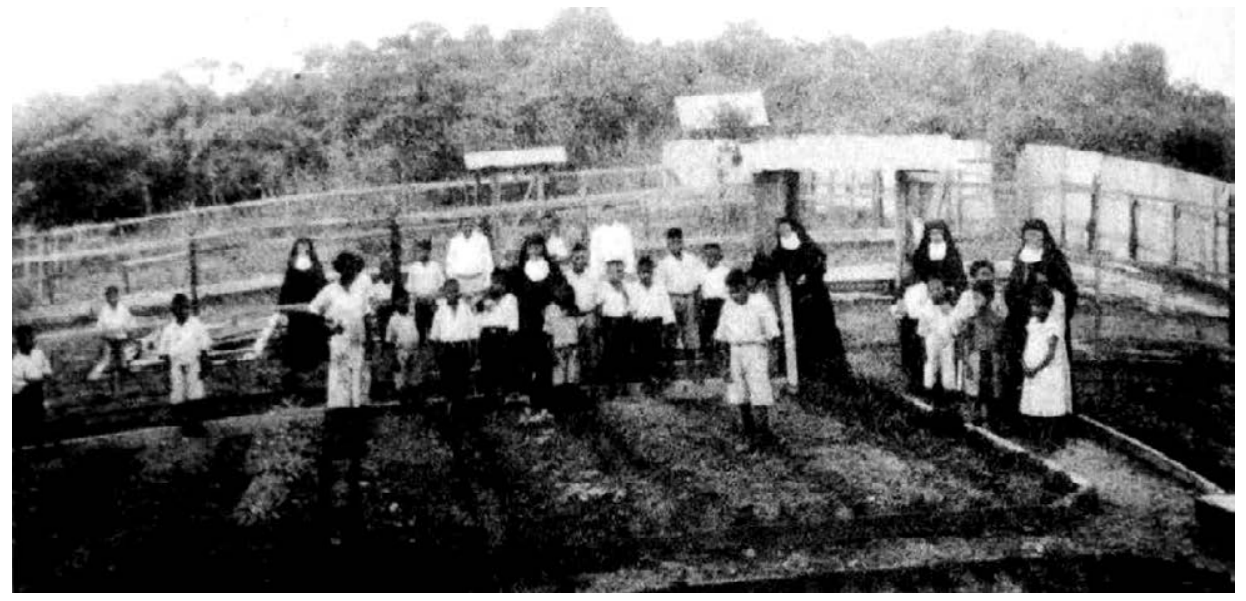

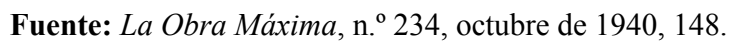


Otro tipo de fotografías que querían dar cuenta de la labor que hacían los misioneros con los neófitos eran las que representaban actos religiosos. Estas son de diferente índole, desde las que escenificaban los distintos sacramentos como el bautizo, comunión o matrimonio -ver fotografías 16,17 y $18-$ y las que plasmaron distintos actos religiosos como, por ejemplo, las procesiones -ver fotografía 19-.

Figura 16. Oficiando un bautizo a dos mujeres gunadule

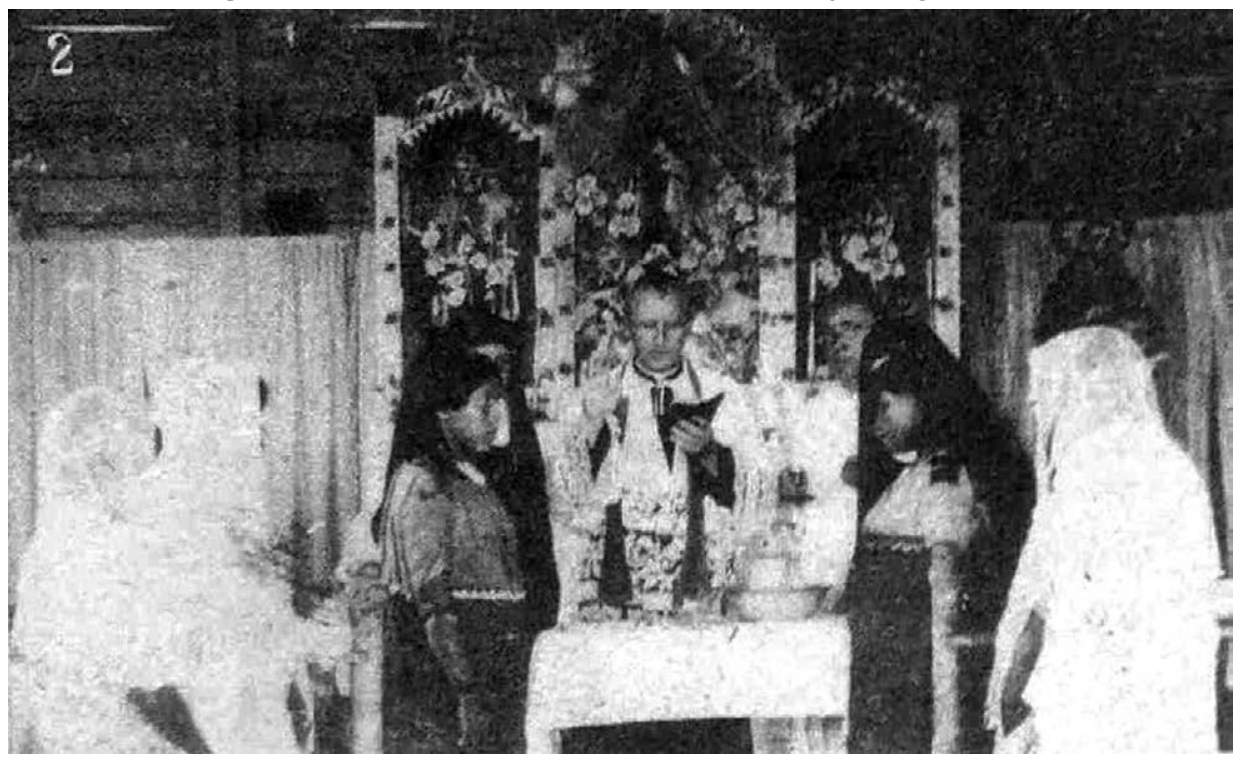

Fuente: La Obra Máxima, n. ${ }^{\circ}$ 239, marzo de 1941, 41.

Figura 17. Escenificación de un bautizo de dos bebés gunadule

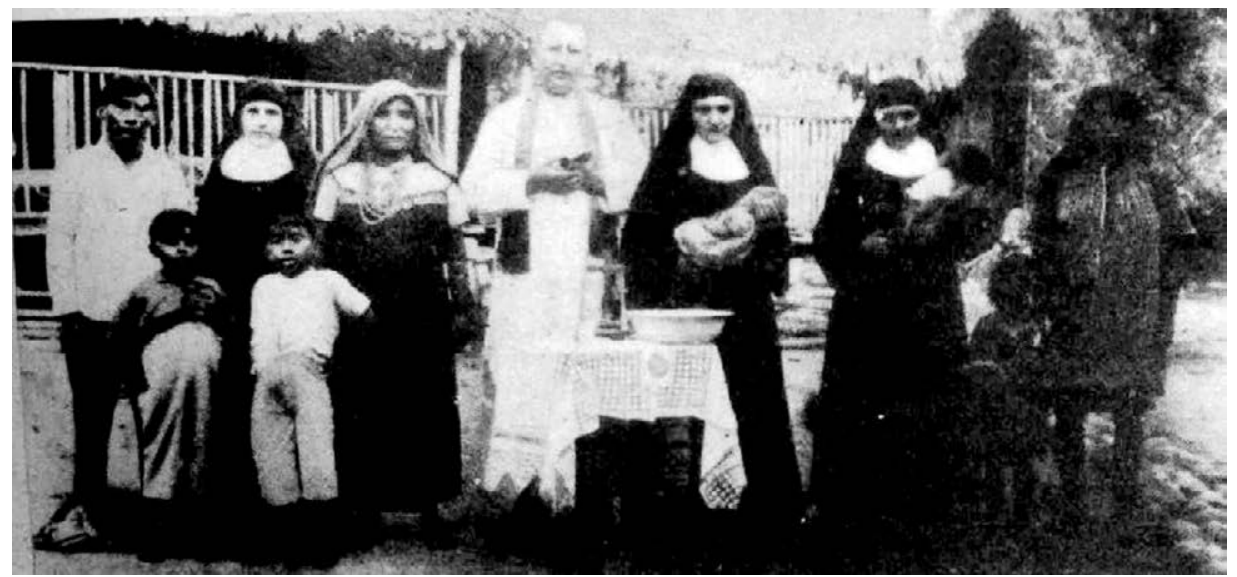

Fuente: La Obra Máxima, n. ${ }^{\circ}$ 346, febrero de 1950, 51. 
Figura 18. Niñas gunadule tomando su primera comunión en el Congreso Eucarístico de Medellín

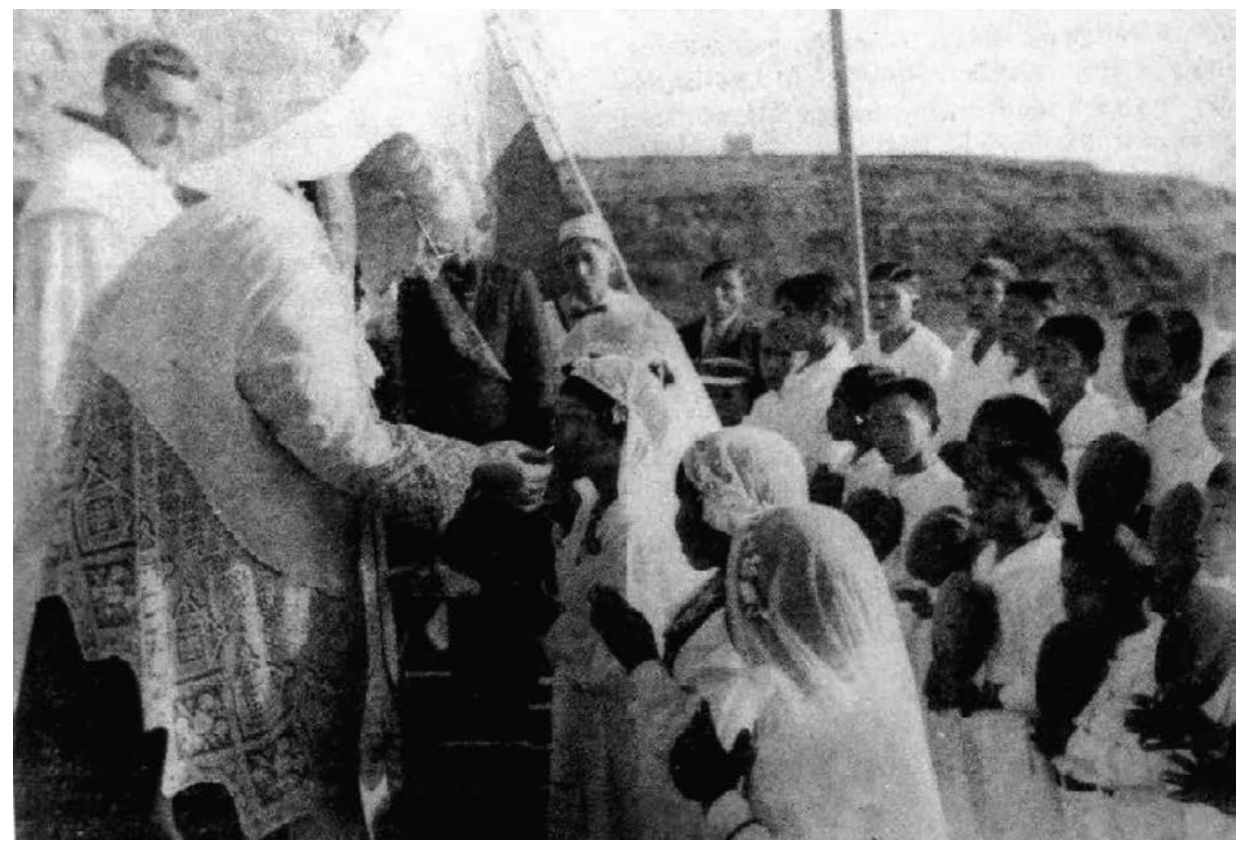

Fuente: La Obra Máxima, n. ${ }^{\circ}$ 180, diciembre de 1935, 364.

Figura 19. Procesión religiosa entre los gunadule de Arquía

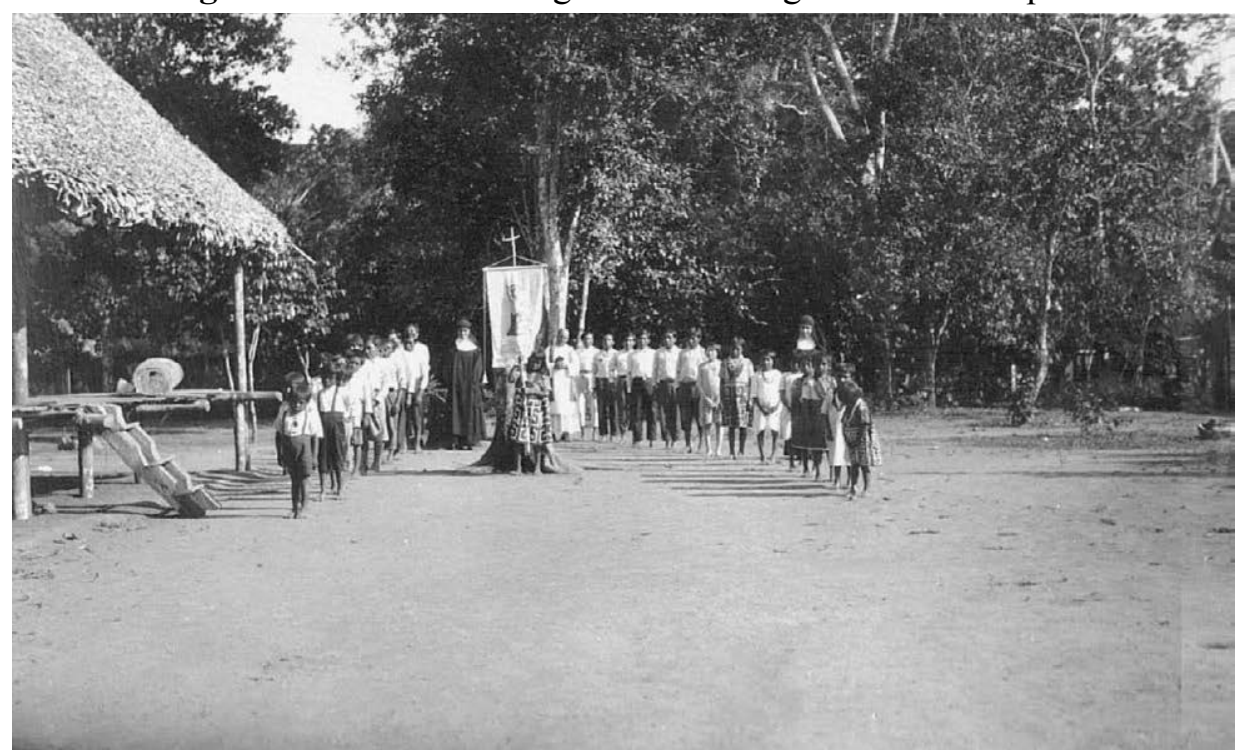

Fuente: FSS-APAU, Material gráfico, caj. 9, núm. 3. 
Tras el análisis de estos momentos capturados en el papel fotográfico por los padres carmelitas descalzos sobre los gunadule del golfo de Urabá, podemos constatar, gracias a las pesquisas realizadas por otras investigaciones relativas a la relación de la fotografía con los procesos de evangelización llevados a cabo por otros misioneros, que todas las representaciones fotográficas tienen patrones en común: mostrar el estado de transición de esos pueblos desde un estado «salvaje» a otro «civilizado». Pudimos observar que los carmelitas descalzos dejaron plasmado ese tránsito al imprimir sobre el papel distintos momentos de la implementación de las prácticas «civilizatorias» para transformar a los indígenas. Estas prácticas, a través de las cuales se querían instaurar determinados hábitos reguladores del tiempo en la vida cotidiana de los indígenas fueron, principalmente, la escolarización de los niños y niñas, la enseñanza de técnicas agrícolas «modernas» y de trabajos manuales además de, obviamente, incorporar a la vida de los nativos los preceptos del catolicismo, elemento indispensable para poder alcanzar la «civilización».

A pesar de este patrón común, considero que podemos establecer algunos matices entre las formas de representar a otros pueblos originarios, por parte de distintas órdenes religiosas, y a los gunadule, por parte de los carmelitas descalzos. Estos matices los ubicamos en la forma como los religiosos miraron a los indígenas que debían «civilizar» en su estado «natural», o sea, en el momento del contacto. Si prestamos atención a las fotografías tomadas y expuestas en la Esposizione d'Arte Sacra e delle Missioni por parte de misioneros franciscanos sobre el pueblo chiriguano, observamos que los retrataron siguiendo la idea estandarizada que se tenía de los indígenas «salvajes»: sin ropa o con un simple taparrabos. ${ }^{45}$

Del mismo modo, los propios carmelitas descalzos y los misioneros claretianos tomaron esta misma posición en referencia a los pueblos embera y embera-catío. Los primeros representaron a los embera-catío de la parte sur de la prefectura apostólica de Urabá y los segundos a los embera de la región del Baudó, en el Chocó, en un «estado de salvajismo» extremo. ${ }^{46}$ Por otro lado, los misioneros capuchinos en el Caquetá y Putumayo no difirieron mucho de sus homónimos pues, para transmitir a quienes observaran las fotografías de los indígenas que debían «civilizar», los mostraban en estado «salvaje», los retrataron portando sus trajes y ornamentación tradicional. ${ }^{47}$ Los salesianos hicieron lo mismo con los habitantes de Tierra del Fuego. ${ }^{48}$

45 García Jordán, «Los Chiriguanos en la Esposizione d'Arte Sacra e delle Missioni e delle Opere Catoliche...», 100.

46 David Díaz Baiges, «Misioneros claretianos en el Chocó en busca de "las pobres gentes abandonadas". La construcción del proyecto misional en la Prefectura apostólica del Chocó, Colombia 1908-1952», Boletín Americanista, n. 78 (2019): 65, https://www.raco.cat/index.php/BoletinAmericanista/article/view/360654.

47 Amada Carolina Pérez Benavides, «Fotografía y misiones: los informes de misión como performance civilizatorio», Maguaré, n. ${ }^{\circ} 30$ (2016): 121, https://revistas.unal.edu.co/index.php/maguare/article/view/62899.

48 Alonso Azocar-Avendaño, Luis Nitrihual-Valdebenito, y Jaime Flores-Chávez, «La Patagonia En Postales fotográficas...», 281. 
En cambio, como pudimos ver, sobre los gunadule no encontramos ningún registro visual que quisiera representar a ese pueblo en estado acusado de «salvajismo». Siempre se los representó, tanto a través de las revistas e informes como en las fotografías, en un estado de tránsito, pues sus ropas, especialmente la de los varones, antes de la llegada de los misioneros ya eran apropiadas para el mundo «civilizado». Al mismo tiempo, su organización socio económica era considerada eficaz y rentable; muestra de ello son las fotografías de sus cacaotales. Por ello, quizás, no se puso tanto énfasis en las imágenes que debían mostrar la transformación de un sujeto improductivo a un miembro útil para la economía nacional, cosa que, tal como destacan Pilar García Jordán entre los chiriguanos y los guarayos, Jaime Flores y Alonso Avendaño entre los mapuches y Amada Carolina Pérez Benavides en el Putumayo, esas fotografías sí tuvieron mucha presencia y protagonismo en las fuentes que analizaron.

Por otro lado, me gustaría destacar la insistencia con que se quiso mostrar la transformación del pueblo gunadule en miembros de la ciudadanía colombiana. Cierto que en las tareas «civilizadoras» de los misioneros de finales del siglo XIX y del XX la conversión del indígena en un sujeto nacional era una de las prioridades. Pero, me ha parecido intuir que en dos casos particulares se puso más énfasis por destacar esta labor. Uno de ellos fue entre los mapuches en las misiones de la Araucanía y el otro entre los gunadule. Tal vez, esto podría estar relacionado con dos aspectos que comparten dichos pueblos. Por un lado, su carácter binacional, pues el pueblo mapuche, tras la «Conquista del desierto», y la «Pacificación de la Araucanía» tenía presencia en territorio argentino y chileno. Lo mismo sucedió con el caso de los gunadule que, tras la independencia de Panamá en el año 1903, quedó dividido por esa nueva frontera nacional.

Por otro lado, multitud de pueblos originarios tienen este carácter binacional, pero, quizás, la trayectoria histórica de resistencia de ambos pueblos frente al avance colonial y, posteriormente estatal sobre sus territorios inquietaba más a los dirigentes nacionales. No debemos olvidar que el pueblo gunadule, en el año 1925, declaró la independencia de su territorio de Panamá. Por ello, barajamos la hipótesis de que la nacionalización de ambos pueblos se convirtió en una prioridad para evitar posibles alianzas que supusieran una pérdida de soberanía de unos territorios donde la presencia estatal era escasa. Esto daría respuesta al destacado protagonismo que los carmelitas descalzos le dieron a la representación del proceso «civilizador» entre el pueblo gunadule a pesar de que, tan solo eran unas 800 personas en Colombia. Con ello querían mostrar que este pueblo era fiel a Colombia y que, por tanto, no comprometerían la soberanía territorial de esa frontera con una acción conjunta con sus hermanos del lado panameño. En definitiva, se puso mucho interés en mostrar a este pueblo como un bastión de la soberanía nacional en esos territorios tan alejados. 


\section{Reflexiones finales}

En este trabajo hemos visto cómo, a través de un conjunto de fotografías, los misioneros carmelitas descalzos elaboraron una determinada imagen del pueblo gunadule. Las representaciones que construyeron fueron un tanto ambivalentes: por un lado, destacaron algunos aspectos culturales de este grupo indígena por ser considerado próximos a lo que los religiosos consideraban «civilizado» $\mathrm{y}$, al mismo tiempo, los detalles de la construcción de esas fotografías querían transmitir que este pueblo todavía no había «evolucionado» lo suficiente como para ser considerado «civilizado» ni, obviamente, sus miembros ser miembros de la ciudadanía colombiana de plenos derechos.

Esto lo hemos podido ver reflejado en las fotografías que muestran el gran potencial del pueblo en la producción agrícola; su modelo de familia acorde con los valores del cristianismo y su gran predisposición a modificar sus praxis sociales. También los representaron como un grupo que, a diferencia de otros pueblos indígenas de la región, iban vestidos, más o menos, de forma «adecuada». Pese a ello, en todas las fotografías percibimos detalles que mostraban el estado de «salvajismo» en que todavía se encontraban.

Con este tipo de fotografías los misioneros estaban no solo legitimando su papel de «civilizadores», sino también justificando su labor apostólica frente a un pueblo que necesitaba de un guía que los condujera hacia el «progreso». Así, mediante las fotografías que daban cuenta de las prácticas «civilizadoras» que implementaron con los neófitos, estaban representando que, gracias a su labor de conversión, ese pueblo, otrora «salvaje», estaba adquiriendo los conocimientos y el comportamiento adecuado para escalar peldaños en esa escala jerárquica que los aproximaba a la puerta de la «civilización».

Por tanto, mediante estas prácticas, los religiosos, con base en sus intereses particulares, estaban construyendo unos «otros internos» diferenciados y necesarios. Necesarios en la medida en que los misioneros necesitaban forjarse una identidad de héroes civilizadores, para lo cual requerían de unos sujetos carentes de las supuestas virtudes representadas en los misioneros.

Para finalizar, concuerdo con los investigadores e investigadoras que apuntan que la continua circulación de las representaciones visuales elaboradas por los misioneros contribuyó a construir o fijar una determinada imagen de las poblaciones indígenas. Al mismo tiempo y partiendo de esta idea, creo que es de vital importancia adentrarse en el proyecto evangelizador mundial del Vaticano a través de Propaganda Fide para establecer, si existía una norma, en referencia a las representaciones visuales, transmitida a los misioneros a través de sus procesos formativos. Si esto fuera así, sería muy interesante abrir un nuevo sendero en el que se hiciera un trabajo comparativo entre las representaciones visuales elaboradas por los misioneros católicos y por los protestantes, quienes desde finales del siglo XIX empezaron a entrar con mucha fuerza en América Latina. 


\section{Bibliografía}

Alverenga Venutolo, Patricia, Mauricio Menjívar Ochoa y María Esther Montanaro Mena. Miradas tramposas. Visiones antropológicas de viajeros por Centroamérica y México, siglos XIX y XX. San José, Costa Rica: EUCR, 2018.

Azocar-Avendaño, Alonso, Luís Nitrihual-Valdebenito y Jaime Flores-Chávez. «La Patagonia en postales fotográficas: Misioneros salesianos y construcción de imaginarios sobre selk nam, Kaweskar y yámanas entre 1880 y 1920». Arte, Individuo y Sociedad 25, n. 2 (13 de mayo de 2013): 271288. https://doi.org/10.5209/rev_ARIS.2013.v25.n2.39040.

Bonilla, Víctor D. Siervos de Dios y amos de indios. El Estado y la misión capuchina en el Putumayo. Cali, Colombia: Universidad del Cauca, 2006.

Briones, Claudia. Cartografías argentinas. Políticas indigenistas y formaciones provinciales de alteridad. Buenos Aires, Argentina: Antropofagia, 2005.

Cabrera Becerra, Gabriel. «La fotografía de misiones y los indígenas del Alto Río Negro-Vaupés de Colombia y Brasil (1914-1965)». História Unisinos, vol. 22, no 1 (enero-abril 2018): 33-49. https://doi.org/10.4013/htu.2018.221.03.

Cabrera Becerra, Gabriel. Los poderes en la frontera. Misiones católicas y protestantes, y Estados en el Vaupés colombo-brasileño, 1923-1938. Medellín, Colombia: Universidad Nacional de Colombia, 2015.

Cabrera Becerra, Gabriel. La Iglesia en la frontera: misiones católicas en el Vaupés, 1850-1950. Bogotá, Colombia: Unibiblos, 2002.

Castro-Gómez, Santiago y Eduardo Restrepo. «Introducción: Colombianidad, población y diferencia». En: Genealogías de la Colombianidad. Formaciones discursivas y tecnológicas de gobierno en los siglos XIX y XX, editado por Santiago Castro-Gómez y Eduardo Restrepo, 10-40. Bogotá: Editorial Pontificia Universidad Javeriana; Instituto de Estudios Sociales y Culturales Pensar, 2008.

Chartier, Roger. «Poderes y límites de la representación. Marín, el discurso y la imagen». En: Escribir las prácticas. Foucault, de Certeau, Marin, editado por Roger Chartier, 73-99. Buenos Aires, Argentina: Manantial, 1996.

Córdoba Restrepo, Juan Felipe. «En tierras paganas misiones católicas en Urabá y en La Guajira, Colombia, 1892-1952». Tesis Doctoral, Universidad Nacional de Colombia, 2012.

Díaz Baiges, David. «Misioneros claretianos en el Chocó en busca de "las pobres gentes abandonadas". La construcción del proyecto misional en la prefectura apostólica del Chocó, Colombia 1908-1952». Boletín Americanista, n. $^{\circ}$ 78 (2019): 51-69. https://www.raco.cat/index.php/BoletinAmericanista/ article/view/360654.

Díaz Baiges, David. "“Convertir para Dios y transformar para la patria”. Misioneros claretianos y carmelitas descalzos entre los "indios errantes" del 
Chocó y Urabá, Colombia (1908-1952)». Tesis Doctoral, Universitat de Barcelona, 2018.

Flores Chávez, Jaime y Alonso Azócar Avendaño. «Rulpachen ka wigkachen pu Mapuche.» Az nentulelu pu kapuchinu patiru Mapuche Mapu Mew/ «Evangelizar, civilizar y chilenizar a los mapuches.» Fotografías de la acción de los misioneros capuchinos en la Araucanía. Sevilla, España: Editorial Universidad de Sevilla/Ediciones Universidad de la Frontera, 2017. Gálvez Abadía, Aída Cecilia. «"Una limosna, caro lector”: la propaganda misionera de los Carmelitas Descalzos de Urabá, Antioquia ». Boletín Cultural y Bibliográfico, vol. 49, n. ${ }^{\circ} 89$ (2015): 25-45. https://publicaciones.banrepcultural.org/index.php/boletin_cultural/article/view/7526.

Gálvez Abadía, Aida Cecilia. Por obligación de conciencia. Los misioneros del Carmen Descalzo en Urabá (Colombia), 1918-1941. Bogotá, Colombia: Instituto Colombiano de Antropología e Historia, 2006.

García Jordán, Pilar. «Los Chiriguanos en la Esposizione d'Arte Sacra e delle Missioni e delle Opere Catoliche en Turín, 1898». En: El mundo latinoamericano como representación, siglos $X I X-X X$, editado por Pilar García Jordán, 99-100. Barcelona, España: Publicacions i Edicions UB /TEIA/ IFEA, 2015.

García Jordán, Pilar. Unas fotografias para dar a conocer al mundo la civilización de la república guaraya. Madrid, España: Consejo Superior de Investigaciones Científicas, 2009.

García Jordán, Pilar. «Yo soy libre y no indio: soy guarayo». Para una historia de Guarayos, 1790-1948. Lima, Perú: IFEA/PIEB/IRD/TEIAA, 2006.

García Jordán, Pilar. Cruz y arado, fusiles y discursos. La construcción de los Orientes en el Perú y Bolivia, 1820-1940. Lima, Perú: Editora IFEA/IEP, 2001.

Gómez López, Augusto Javier. «El Valle de Sibundoy: el despojo de una heredad. Los dispositivos ideológicos, disciplinarios y morales de la dominación». Anuario Colombiano de Historia Social y de la Cultura, n. ${ }^{\circ} 32$ (2005): 5173. https://revistas.unal.edu.co/index.php/achsc/article/view/8189.

González Escobar, Luís Fernando. El Darién. Ocupación, poblamiento y transformación ambiental. Una revisión histórica. Parte II. Medellín, Colombia: Instituto Tecnológico Metropolitano, 2012.

Guiteras Mambiola, Anna y Pilar García Jordán. «El "otro" sirionó, objeto de la misión "civilizadora" del Núcleo Escolar Selvícola de Casarabe». En: $L a$ reinvención de América. Proyecciones y percepciones Europa-América Latina, siglos XIX-XX, editado por Pilar García Jordán, 45-80. Barcelona, España: Publicacions i Edicions UB /TEIA/ IFEA, 2017.

Kuan Bahamón, Misael. «La misión capuchina en el Caquetá y el Putumayo 1893-1929». Tesis de Maestría, Pontificia Universidad Javeriana, 2013. 
Howe, James. Un pueblo que no se arrodillaba. Panamá, los Estados Unidos y los Kunas de San Blas. Miami, Estados Unidos de América: Plumsock Mesoamerican Studies; Centro de Investigaciones Regionales de Mesoamérica, 2004.

Nicoletti, María Andrea. Indígenas y misioneros en la Patagonia: huellas de los salesianos en la cultura y religiosidad de los pueblos originarios. Buenos Aires, Argentina: Continente, 2008.

Pérez Benavides, Amada Carolina. «Fotografía y misiones: los informes de misión como performance civilizatorio». Maguaré, n. 30 (2016): 103-139. https://revistas.unal.edu.co/index.php/maguare/article/view/62899.

Pérez Benavides, Amada Carolina. Nosotros y los otros. Las representaciones de la nación y sus habitantes. Colombia, 1880-1910. Bogotá, Colombia: Editorial Pontificia Universidad Javeriana, 2015.

Rausch, Jane. La frontera de los llanos en la historia de Colombia (1830-1930). Bogotá, Colombia: Banco de la República, 1999.

Santa Teresa, Severino de. Historia documentada de la iglesia en Urabá y el Darién: desde el descubrimiento hasta nuestros días. Vol.5 Época de la América Española Independiente (1810-1956) (La prefectura apostólica de Urabá). Bogotá, Colombia: Empresa Nacional de Publicaciones, 1956.

Steiner, Claudia. Imaginación y poder. El encuentro del interior con la costa en Urabá, 1900-1960. Medellín, Colombia: Editorial Universidad de Antioquia, 2000.

Wade, Peter. Música, raza y nación. Música tropical en Colombia. Bogotá, Colombia: Vicepresidencia de la República de Colombia; Departamento Nacional de Planeación; Programa Plan Caribe, 2002. 